\title{
MATERIAIS CORRETIVOS APLICADOS NUM LATOSSOLO \\ VERMELHO-ESCURO COM CULTURA DE CITROS
}

\author{
VALTER CASARIN \\ Engenheiro Agrônomo
}

Orientador: Prof.Dr. GODOFREDO CESAR VITTI

Dissertação apresentada à Escola Superior de Agricultura "Luiz de Queiroz", da Universidade de são Paulo, para obtenção do título de Mestre em Agronomia, Área de Concentração: Solos e Nutrição de Plantas. 
Ficha catalografica preparada pela Sefao de Livros da Divisáo de Biblioteca e Documentaģo - FCLO/UBP

\footnotetext{
Casarin, valter

ç35m Materiais corretivos aplicados num latossolo vermelho-escuro con cultura de citros. Firacicabas 1794 .

$61 \mathbf{p}$.

Diss - Mestre) - ESALO

Eibliografia.

1. Calagen 2. Gesso agricola 3. Solo-Acidez I. Es cola Superior de Agricultura Luiz de Queiroz. Firacica ba
}

CDD 631.42 


\section{MATERIAIS CORRETIVOS APLICADOS NUM LATOSSOLO VERMELHO-ESCURO COM CULTURA DE CITROS}

VALTER CASARIN

Aprovada em 09.03.1994

Comissão julgadora: -

Prof.Dr. Francisco Antonio Monteiro

USP/ESALQ

Prof.Dr. Leonardo Theodoro Bull

UNESP/FCA

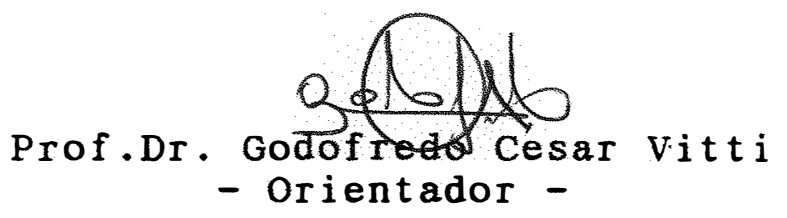


$H O M E N A G E M$

Aquela que me incentivou e apoiou nos momentos dificeis, cuja vida foi dedicada aos filhos. Hoje a saudade sufoca meu peito, mas seu exemplo é meu forte estímulo.

Minha mãe: HELENA ZAMBELLO DAMATRIZ

"In memorian" 
i .

Aos meus pais Antonio Casarin (in memorian) e Mário Damatriz, e meus irmão Vitório, Vladimir e Vagner.

$$
\text { ofereço. }
$$

A minha esposa Meire e ao nosso filho Nicolas,

Dedico com eterna gratidão. 


\section{AGRADECIMENTOS}

- Ao Professor Dr. Godofredo Cesar Vitti, do Departamento de Ciência do Solo, pela orientação desta dissertação;

- Ao Professor Dr. Francisco Antonio Monteiro, do Departamento de Química, pela colaboração na correção desta dissertação;

- Ao Sr. José Irineu Rosolen, pela oportunidade de utilizar o Sítio Boa Vista para implantação do experimento de campo;

- A Escola Superior de Agricultura "Luiz de Queiroz", que possibilitou minha participação no curso de Pós-Graduação;

- Ao Conselho Nacional de Desenvolvimento Cientifico e Tecnológico (CNPq), pela concessão de bolsa de mestrado;

- A Magnesita S.A., pela cessão do produto magnesita;

- Ao Prof.Dr. Eurípedes Malavolta, pelo auxílio na confeção do summary;

- Aos Srs. Jair Ferrer da Silva e Dorival Grissotto, pela colaboração na execução deste trabalho;

- A Sra. Marta Sueli de C. Ferraz, pelo trabalho de digitação;

- Ao amigo e "irmão" Engo florestal Ronaldo Luiz Vaz de Arruda Silveira, pela amizade e apoio nos momentos difíceis;

- A todos que, de alguma forma, colaboraram para a realização deste trabalho. 
i i i .

S U M A R I O

Página

RESUMO $\ldots \ldots \ldots \ldots \ldots \ldots \ldots \ldots \ldots \ldots \ldots \ldots \ldots \ldots \ldots \ldots \ldots$

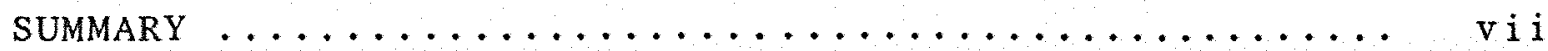

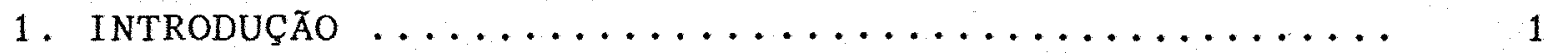

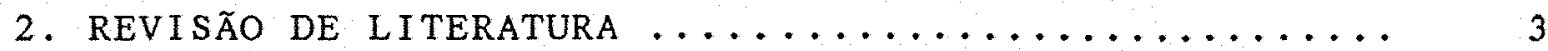

2.1. Funções do cálcio, magnésio e enxofre....... 3

2.2. Aspectos gerais sobre acidez dos solos....... 4

2.3. Materiais Corretivos............... 7

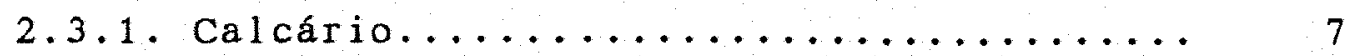

2.3 .2 . Gesso Agrícola................. 8

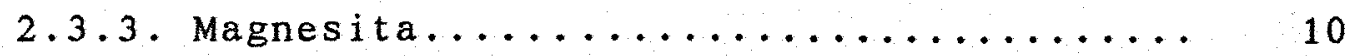

2.4. Respostas dos citros à calagem.......... 11

3. MATERIAL E METODOS......................... 13

3.1 . Solo........................... 13

3.2. Características do pomar............... 14

3.3. Tratamentos..................... 14

3.4. Delineamento e anál ise estatística ........ 16

3.5. Tratos culturais.................. 16

3.6. Avaliações....................... 18

3.6.1. Amostragens e análises foliares....... 18

3.6.2. Amostragens e análise do solo......... 19

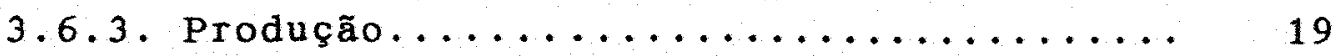

3.6 .4 . Características dos frutos......... 20

3.6 .5 . Análise tecnológica............. 20

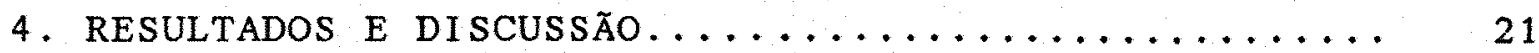

4.1. Análise química do solo................ 21

4.1 .1 Ano agrícola $1990 / 91 \ldots \ldots \ldots \ldots \ldots \ldots \ldots \ldots \ldots$

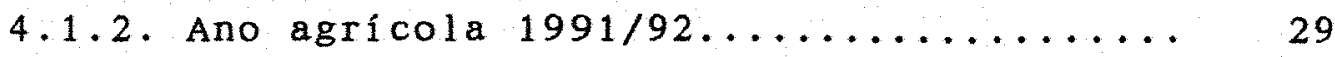

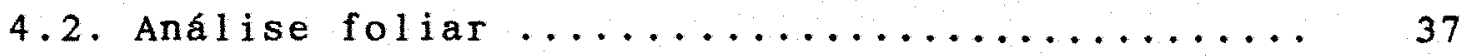

4.2 .1 . Ano agrícola $1990 / 91 \ldots \ldots \ldots \ldots \ldots \ldots \ldots$

4.2 .2 . Ano agrícola $1991 / 92 \ldots \ldots \ldots \ldots \ldots \ldots \ldots$

4.3 . Produção de frutos.................... 44 
Página

4.4. Análises tecnológicas.............. 46

4.4.1. Ano agrícola $1991 / 92 \ldots \ldots \ldots \ldots \ldots \ldots \ldots$

4.4.2. Ano agrícola $1992 / 93 \ldots \ldots \ldots \ldots \ldots \ldots \ldots$

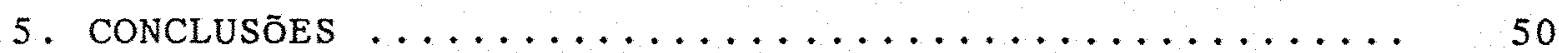

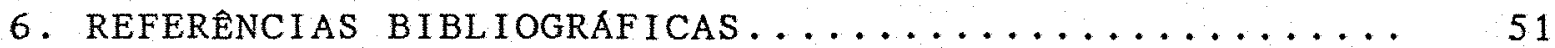




\title{
MATERIAIS CORRETIVOS APLICADOS NUM LATOSSOLO VERMELHO-ESCURO COM CULTURA DE CITROS
}

\author{
Autor: VALTER CASARIN \\ Orientador: Prof.DT . GODOFREDO CESAR VITTT
}

RESUMO

O presente trabal ho foi realizado com o objetivo de testar a eficiencia de diversos materiais corretivos da acidez do solo, de forma isolada ou associado ao gesso agrícola, no estado nutricional da planta, na qualidade e produção de frutos e na fertilidade do solo, o experimento foi realizado com oito tratamentos: testemunha, calcario calcítico, calcário magnesiano, calcário dolomítico, calcário dolomítico $(70 \%)$ - gesso $(30 \%)$, magnesita $(25 \%)$ + calcário calcítico $(75 \%)$, magnesita $(15 \%)+$ calcário calcítico $(85 \%)$ e magnesita $(15 \%)+$ gesso $(85 \%)$, dispostos em blocos casualizados com cinco repetições, sendo cada parcela constituída de cinco plantas úteis, num pomar de laranjeira pêra enxertada sobre limão Cravo, com três anos de idade, em um Latossolo Vermelho-Escuro, textura média, distrófico (LEd).

A condução do experimento ocorreu durante o terceiro, quarto e quinto ano da instalação do pomar, respectivamente nos anos agrícolas 1990/91, 1991/92 e 1992/93. Nesse período foram feitas avaliações da análise de solo nas profundidades de $0-20,21-40$ e $41-60 \mathrm{~cm}$, da análise foliar, da 
vi.

análise tecnológica dos frutos e da produção. Os resultados obtidos demonstraram que a utilizaça de corretivos promoveu o aumento do $\mathrm{pH}$ e praticamente anulou a saturação por alumínio nas profundidades estudadas. A utilização da magnesita na composição de corretivos proporcionou eficiente correção da acidez superficial do solo, bem como adequado fornecimento de magnésio. A produção de frutos obtida no tratamento composto pelos produtos magnesita $(15 \%)$ e gesso $(85 \%)$ foi significativamente maior que a da testemunha. Por outro lado, coube ao tratamento sem aplicação de corretivos (testemunha) a menor produção de frutos por planta. A presença do gesso, propiciou níveis adequados de $\mathrm{K}, \mathrm{Ca}, \mathrm{Mg}$ e $\mathrm{S}$ ao longo do perfil do solo. 
vi i.

\title{
LIMING MATERIALS APPLIED TO A DARK RED LATOSSOL SUPPORTING AN ORANGE ORCHARD
}

\author{
Author: VALTER CASARIN \\ Adviser: Prof.Dr. GODOFREDO CESAR VITTI
}

SUMMARY

The present experiment was carried out with the goal of studying the effect of several soil acidity amendments, either isolated or in association with phosphogypsum, on soil fertility, nutritional status, yield and quality of citrus, Pera/Rangpur lime, using a grove with 3 year old plants located in a Dark Red Latosol, medium texture.

The following treatments each one with five useful plants, with five replications, were used: control, calcitic limestone, magnesian limestone (70\%), dolomitic limestone, dolomitic limestone $(70 \%)+$ phosphogypsum $(30 \%)$, magnesite $(25 \%)+$ calcitic limestone $(75 \%)$, magnesite $(15 \%)+$ calcitic limestone (85\%), magnesite $(15 \%)+$ phosphogypsum $(85 \%)$.

The trial was conducted during the third $(1990 / 91)$, fourth $(1991 / 92)$ and fifth (1992/93) year after the grove was planted. 
viii.

The results showed that lime application, alone or added to phosphogypsum and magnesite, was responsible for a pH raise and a decrease in aluminum percentage saturation in the soil depths studied. Magnesite added to lime was responsible for an efficient acidity reduction in the soil surface, and for an adequate supply of magnesium. The orange production obtained in the magnesite (15\%) and phosphogypsum ( $85 \%)$ treatment was significantly higher than in the control plants, which had the lowest production (fruits/plant) in the experiment. The phosphogypsum application was responsible for providing adequate $\mathrm{K}, \mathrm{Ca}, \mathrm{Mg}$ and $\mathrm{S}$ throughout the soil profile. 


\section{INTRODUÇÃO}

Os solos ácidos no Brasil predominam em quase todas as regióes, só ocupando menores áreas no semi-árido nordestino.

A crescente expansão da citriculturabrasileira tem levado os produtores a implantar seus pomares em diversos tipos de solos, com problemas sérios de saturação por alumínio trocável e baixos teores de cálcio e magnésio, limitando o pleno crescimento das raízes, afetando, assim, o desenvolvimento das plantas.

A correção da acidez do solo, bem como um programa adequado de adubação, pode constituir em um fator preponderante para o aumento da produtividade dos pomares citrícolas. E por intermédio da calagem que se corrige a acidez do solo. Entretanto, os efeitos desta correção ficam restritos à camada arável do solo, permanecendo a camada sub-superficial em condições de acidez, limitando o crescimento radicular e, como conseguinte, afetando a absorção de água e nutrientes, principalmente em culturas perenes.

Em anos recentes, grande interesse surgiu na procura de meios para diminuir o problema da acidez subsuperficial, principalmente sem a incorporaça profunda do 
calcário. Desta forma, o gesso agrícola é uma alternativa importante, por apresentar maior mobilidade no perfil do solo, aumentar o teor de Ca do solo e reduzir a saturação do alumínio toxico.

Por outro lado, a utilização exclusiva do gesso, promove o movimento de bases para os horizontes inferiores, tornando o solo pobre em $\mathrm{K}$ e $\mathrm{Mg}$, principalmente, na camada arável do solo. Esse problema pode ser solucionado efetuando a gessagem após, ou juntamente, à calagem, em proporções equilibradas, principalmente em solos com pouco calcio e muito a lumínio abaixo da camada arável.

Uma outra alternativa para correça da acidez do solo é a utilização do óxido de magnésio (Mgo), um produto obtido a partir da calcinação do mineral magnesita $\left(\mathrm{MgCO}_{3}\right)$.

Em vista do exposto, o presente trabalho foi realizado com o objetivo de testar a eficiencia de diversos materiais corretivos da acidez do solo, de forma isolada ou associado ao gesso agrícola, visando a melhoria do ambiente de desenvolvimento radicular das plantas e, consequentemente, a obtenção de produção mais elevada e de melhor qualidade. 
2. REVISÃO DE LITERATURA

2.1. Funções do cálcio, magnésio e enxof re

Segundo KAMPFER \& UEXKULL (1966), a absorção de elementos minerais pelos citros ocorre durante todo $o$ ano, sendo maior no período do florescimento e quando da formação de folhas e ramos novos, que no hemisfério sul ocorre em setembro/dezembro e março/abril. os autores concluiram que a absorção de nutrientes do solo e afetada negativamente pelas baixas temperaturas, sendo esse efeito menos acentuado para os elementos $\mathrm{N}$ e Ca e mais pronunciado para $0 \mathrm{~K} \mathrm{e} \mathrm{Mg}$.

BATAGLIA et al. (1977) verificaram que uma caixa de laranjas de 40,8 kg proporcionava a exportação de macronutrientes de acordo com a seguinte ordem decrescente: $N$, $\mathrm{K}, \mathrm{Ca}, \mathrm{P}, \mathrm{S}, \mathrm{Mg}$.

As plantas cítricas são calcifilas, pois é o nutriente cálcio que elas possuem em mais alta proporção, sendo que, QUAGGIO (1985) considerou os citros como uma das poucas espécies onde observam-se teores foliares de cálcio superiores ao nitrogênio.

Com relação às funções do cálcio, Malavolta et a l. (1989) as dividiram em: a) estrutural: pectatos de cálcio, 
carbonato de cálcio, oxalato de cálcio, fitato de calcio e calmodulinas; b) constituinte ou ativador enzimático: ATPase (aspirase), alfa amilase, fosfolipase D, nucleases; c) processos: estrutura e funcionamento de membranas, absorção. iônica, reações com hormônios vegetais e ativação enzimatica; d) papéis na formação: estimula o desenvolvimento das raízes e aumenta o pegamento das floradas.

O magnésio é o elemento central da molécula de clorofila, citado em NEPTUNE (1984). Segundo MALAVOLTA (1979), - magnésio atua como transportador de fosfato, uma vez que ele é móvel dentro da planta e nas partes onde as concentraçóes de fósforo são altas, isto é, sementes e tecidos meristemáticos, também ocorrem altos níveis de magnésio.

O enxofre é um elemento essencial ao crescimento e desenvolvimento das plantas, desempenhando funções vitais no metabol ismo, sendo componente dos aminoácidos cistina, cisteina e metionina, além de participar no metabolismo das albuminas e em reações enzimáticas (MALAVOLTA, 1980 e MENGEL \& KIRKBY, 1982). Além disso, o enxofre esta ligado às vitaminas biotina e tiamina; é componente do acetil-CoA; os grupos sulfidricos (-SH) do tecido vegetal parecem aumentar a resistência da planta ao frio e à seca (VITTI et al., 1988).

\subsection{Aspectos gerais sobre acidez dos solos}

Os solos tropicais são normalmente acidos, seja pela ocorrência de precipitação suficientemente alta para lixiviar quantidades apreciáveis de bases trocáveis, seja pela ausência de minerais primários e secundários responsáveis pela reposição das mesmas (VITTI, 1984a). A utilização de fertilizantes, principalmente os nitrogenados, aplicados de forma localizada e em doses elevadas, promovem a aceleração do processo de acidificação do solo, agravando os problemas de toxicidade devido ao excesso de íns alumínio e/ou manganês, 
reduzindo, desta forma, a eficiência dos fertilizantes (VITTI \& DONADIO, 1988 ).

Atualmente, os pomares citricos paulistas encontram-se em solos com excesso de acidez, conforme levantamento de resultados de análise de solo efetuado por RAIJ (1985). Segundo OLIVEIRA (1986), as plantas cítricas são sensiveis à acidez e muito exigentes em cálcio, principalmente, e magnésio. Desta forma, correções periódicas dos solos pela aplicação de materiais corretivos, para que se não limite a produção agrícola, torna-se um processo inevitável (GUILHERME, $1986)$.

As pesquisa têm-se referido, em sua maioria, à correção da acidez na camada arável do solo. No entanto, a presença do alumínio nos horizontes subsuperficiais causa restrição ao desenvolvimento radicular das culturas, tornandose um obstáculo à maximização das produções, pois o volume de solo explorado pelo sistema radicular é insuficiente para atender as necessidades de água e nutrientes da planta (OLMOS \& CAMARGo, 1976). Outro efeito do alumínio se refere à capacidade de $\mathrm{f}$ ixação do fósforo em formas menos disponíveis no solo e/ou nas plantas (TISDALE et al., 1985).

Além da presença do alumínio, o aprofundamento do sistema radicular pode também ser impedido por níveis baixos de cálcio no subsolo (PAVAN, 1986).

A calagem pode resolver o problema da toxidez de alumínio e de deficiência de cálcio na camada superficial do solo, não o fazendo, no entanto, nas camadas mais profundas (RAIJ, 1988). A incorporação de calcário a profundidades maiores que aquela normalmente utilizada na aração é prática onerosa e de difícil execução, uma vez que necessita de equipamentos apropriados que não são encontrados normalmente no mercado (MART INS, 1990 ).

Segundo MALAVOLTA (1988), a faixa de pH em torno de $6,0-6,5$ parece ser a mais adequada ao desenvolvimento e a 
produção dos citros. Para RAIJ (1983), a faixa de saturação por bases entre 60 e $70 \%$ seria a mais indicada para a cultura dos citros.

A calagem é prática indispensável e suficiente para corrigir a acidez superficial, no entanto, não desce com facilidade no perfil do solo, particularmente nos solos argilosos mais pesados (VITTI \& DONADIO, 1988).

A presença de barreiras químicas nas camadas subsuperficiais, não alcançadas usualmente pela calagem, impede - desenvolvimento do sistema radicular, em função do efeito prejudicial do excesso de alumínio e manganês e da baixa participação do cálcio no complexo de troca (FOY, 1984). Como consequência, relataram MALAVOLTA \& VIOLANTE NETTO (1989), as plantas ficam com as rafzes mais superficiais e por isso resistem menos à seca, já que as camadas superficiais são as primeiras a perder água, além de fazer com que as plantas aproveitem menos da fertilidade natural do solo e absorvam menos do fertilizante aplicado.

A aplicação do gesso agrícola na superfície do solo tem sido proposta como uma alternativa para solucionar esse problema, pois a lixiviaça do calcio promove o enriquecimento do perfil do solo, com consequente diminuiça da saturação de alumínio do subsolo, facilitando o crescimento das raízes nessas camadas, bem como o fornecimento de enxofre (RITCHEY et al., 1980; PAVAN et a 1., 1984; HAMMEL et al., 1985; SUMNER et al., 1986; CHAVES et al., 1988; FARINA \& CHANNON, $1988 \mathrm{~b}$ ). 


\subsection{Materiais Corretivos}

\subsubsection{Calcário}

Segundo QUAGGIO (1985), a cultura de citros é responsável por $1 / 3$ do consumo de calcário no Estado de São Paulo, demonstrando, desta forma, a baixa utilização do calcário na agricultura paulista.

os materiais que podem ser utilizados na correção da acidez dos solos são aqueles que contém como "constituinte neutralizante" ou "princípio ativo", óxidos, hidróxidos, carbonatos e silicatos de cálcio e ou magnésio (ALCARDE, 1985).

Calcário é o carbonato de cálcio natural que se encontra abundantemente na crosta terrestre, apresentando-se em extensas e espessas camadas e em lentes intercalares nas formações sedimentares e metamórficas nos diversos períodos geológicos, conforme froes Abreu ${ }^{1}$, citado por MALAVolTa (1981).

Para fins práticos, Malavolta (1981) propôs uma classificação em função dos teores de CaO e Mgo presentes nos calcários, onde: calcários calcíticos, quando o teor de cao é de $40-45 \%$ e de Mgo de 1 a $5 \%$; calcários magnesianos, quando o teor de $\mathrm{CaO}$ é de 30 a $40 \%$ e o de MgO de 6 a $12 \%$, e calcários dolomíticos com 25 a $30 \%$ de CaO e 13 a $20 \%$ de Mgo.

Em estudos feitos com as amostras de solos analisadas pelo Instituto Agronômico, QUAGGIO (1982) observou que $50 \%$ dos pomares encontram-se em solos de elevada acidez. Por outro lado, QUAGGIO (1985) verificou que os citricultores não fazem uma adequada correção do solo antes da implantação da cultura. A localização do calcário na cova e a correção do solo em area total nos anos subsequentes, tem sido a forma preferida

1 FROES ABREU, $S$. Recursos Minerais do Brasil. São Paulo, Edit. Edgard Blucher Ltda., 1973. V.I, p.136-147. 
dos citricultores, tornando, assim, o processo de correção de acidez mais demorado.

A recomendação de calagem tem sido feito utilizando-se o método baseado na correlação entre o pH e a saturação por bases (V\%) do solo, procurando-se elevar o V para cerca de $60-70 \%$, que corresponde a valores aproximados de 6,0 para pH em água e de 5,5 para pH em $\mathrm{CaCl}_{2}$ (QUAGGIO, 1982).

\subsubsection{Gesso Agrícola}

O gesso agrícola é originário da reaça de ácido sulfúrico sobre rocha fosfatada, realizada com a finalidade de produzir ácido fosfórico (RAIJ, 1988). De acordo com ROBINSON (1980), para cada tonelada de $\mathrm{P}$, são produzidas cerca de 11 toneladas de gesso. PAOLINELLI et al. (1986) indicaram que há uma sobra de 4,5 toneladas de gesso agrícola para cada tonelada de $\mathrm{P}_{2} \mathrm{O}_{5}$ produzida.

VITTI (1987) definiu o gesso agrícola como um sal neutro, o qual não afeta a reação do solo; apresenta-se na forma de pó branco, revelando em sua composição aproximadamente 15 a $17 \%$ de umidade livre; 26 a $28 \%$ de CaO e 15 a $16 \%$ de s e solubilidade em água de $0,204 \mathrm{~g} / 100 \mathrm{ml}$ a $20^{\circ} \mathrm{C}$.

As recomendações do gesso agrícola visando enriquecer em Ca, diminuindo a porcentagem de saturaça em alumínio (valor $\mathrm{m}$ ) em subsuperfícies, devem ser feitas em áreas que apresentam nas camadas subsuperficiais (abaixo de $20 \mathrm{~cm}$ ) toxidez de $\mathrm{Al}^{3+}$ e deficiência de $\mathrm{Ca}^{2+}$. Quanto às doses deve se lembrar que ainda falta metodologia adequada. Um critério muito usado para o cálculo da dose de gesso é baseado na dose de calcário ( 25 a $30 \%$ da quantidade de calcário) sem prejuízo da quantidade desse corretivo (VITTI, 1987). Outro critério, foi recomendado por MALAVOLTA \& VIOLANTE NETTO (1989), com base na equivalência com cálcio (menor que 2,0 meq/100 $\mathrm{cm}^{3}$ ) e alumínio (maior que $0,5 \mathrm{meq} / 100 \mathrm{~cm}^{3}$ ), de ańlises de solo a 
profundidade de $21-40 \mathrm{~cm}$. Tendo a restrição de aplicar o gesso agrícola em quantidades inferiores a 1,5 toneladas por ano. SOUSA et al. (1992), recomendaram a necessidade de gesso em solos de cerrado através do teor de argila do solo, do s retido na fase sólida/S na solução e do Ca retido na fase sólida/Ca na solução.

LOPES (1986) recomenda a dose de gesso levandose em consideração o teor de argila nas camadas subsuperficiais $\left(20 \mathrm{~cm}\right.$ ou mais), quando o teor de Ca for menor que $0,3 \mathrm{meq} / 100 \mathrm{~cm}^{3}$ ou quando o teor de Al for maior que $0,5 \mathrm{meq} / 100 \mathrm{~cm}^{3}$ e/ou a saturação de Al na CTC efetiva for igual ou maior que $40 \%$.

VITTI (1984b), considerou o equilíbrio da relação $\mathrm{Ca} / \mathrm{Mg}$, outro uso do gesso na citricultura, de maneira a elevar a concentração de Ca no solo. Conforme VITTI \& DONADIo (1988), para se elevar o teor de Ca no solo, considera-se que a aplicação de $1,0 \mathrm{t} / \mathrm{ha}$ de gesso agrícola, com $17 \%$ de umidade, corresponde aproximadamente a $0,50 \mathrm{meq} \mathrm{Ca} / 100 \mathrm{ml}$ TFSA.

REEVE \& SUMNER (1972), RIRIE et a 1. (1952),

RITCHEY et a 1. (1980), QUAGGIO et al . (1982) e PAVAN et al. (1984), relataram que a aplicação de gesso tem sido responsável pela lixiviação de potássio e magnésio. Quando se trata do potássio, a preocupação se torna importante, uma vez que esse nutriente é caro e quase totalmente importado (RAIJ, 1988).

No entanto, QUAGGIO et al . (1982) constataram perdas menores de $\mathrm{K}$ quando na presença de doses mais elevadas de calcário. Da mesma forma, EMBRAPA (1982), em ensaios conduzidos em condiçóes de coluna e de campo, verificou uma lixiviação de potássio menos intensa quando se aplicou calcário e gesso em relação à aplicação isolada de gesso.

REEVE \& SUMNER (1972), em estudos em casa de vegetação, verificaram perdas de mais da metade do Mg nativo em condições de elevadas doses de gesso (acima de 3,0 meq/100g).

o problema da lixiviação pode ser contornado, segundo PAVAN et al. (1984), através da aplicação de calcário 
e gesso em proporções equilibradas, uma vez que, a precipitação é suficiente para realizar a "lixiviação" do gesso para o subsolo.

DEMATTÊ (1986), testando o uso de gesso e calcário, verificou o aumento no teor de $\mathrm{Ca}, \mathrm{Mg}$ e $\mathrm{S}-\mathrm{SO}_{4}$ na superfície e em profundidade, bem como da porcentagem de saturação por bases ( $V \%)$, ocorrendo, também, diminuição na concentração de Al trocável e enriquecimento de $\mathrm{K}$ trocável em camadas mais profundas.

VITTI \& DONADIO (1988) recomendaram a aplicação conjunta de gesso e calcario, pois o efeito de ambos se complementam, sendo que o gesso não substitui o calcário.

\subsubsection{Magnesita}

Além do calcário tradicional e do gesso agrícola, sub-produto da fabricação do ácido fosfórico (VITTI et al., 1988), surge também a utilização do óxido de magnésio, produto obtido da calcinação do mineral magnesita $\left(\mathrm{MgCO}_{3}\right)$, como corretivo de acidez e fornecedor do nutriente magnesio, contendo $95 \%$ MgO e com PN de aproximadamente $206 \%$.

SILVA \& DEFELIPO (1989), utilizando a magnesita e o gesso em eucalipto, verificaram, após um ano de plantio, aumento do volume tanto para a aplicação isolada de gesso como para a de magnesita.

Objetivando verificar a influência da adição de magnesita ao superfosfato triplo e ao gesso, visando alcançar uma melhor relação $\mathrm{P}_{2} \mathrm{O}_{5} / \mathrm{MgO}$ e CaO/Mgo em um Latossolo Vermel ho Escuro, com correção da acidez através da calagem, DEFELIPo et al. (1990), concluiram que a soja respondeu somente à presença da magnesita, enquanto o milho respondeu ao gesso, além de uma interação positiva entre magnesita e superfosfato triplo na produção da soja. 
DEFELIPO et a l. (1989) estudaram a influência da magnesita na adubação com superfosfato triplo em solos de cerrado que haviam recebido calcário calcítico, no cultivo de milho e soja. Verificaram respostas positivas para a magnesita, tanto para o milho como para a soja.

\subsection{Respostas dos citros à calagem}

São escassos os resultados experimentais sobre - efeito da calagem no Brasil.

CIPOLLI (1986), trabalhando em um Latossolo Vermelho-Escuro, textura média, distrófico de Bebedouro (SP), depois da calagem em área total, foi aplicado calcário dolomítico e gesso, isolados ou juntos, na cova. Verificou-se, um ano após o plantio, que os tratamentos influenciaram o crescimento das plantas, bem como os teores foliares de cálcio e de magnésio, sugerindo ser devido exclusivamente ao calcário o motivo desse efeito.

ANDERSON (1987), conduziu, em solo arenoso da F16rida (EUA), um experimento com laranjeira "Valência" num pomar irrigado. Os tratamentos foram: (1) testemunha; (2) calcário dolómítico o quanto necessário para manter o $\mathrm{pH}$ do solo em 7,0 ; (3) combinações de calcário calcítico e gesso para manter o $\mathrm{pH}$ em 7,0 e fornecer $224 \mathrm{~kg} / \mathrm{ha}$ de $\mathrm{Ca}$ (inicialmente calcário calcítico e posteriormente gesso quando o pH atingiu o valor 7,0$)$. o experimento começou quando as árvores atingiram 2 anos de idade e continuou por 15 anos. Os dois tratamentos com calcário dobraram a produção, não havendo diferença significativa entre os mesmos. A produção de frutos teve relação direta com o aumento do tamanho das árvores, sendo esse crescimento duas vezes mais rápido que as árvores onde não foi feita a calagem.

QUAGGIO et al. (1992), trabalharam durante 7

anos com laranjeira Valencia sobre limoeiro Cravo para 
12.

verificar a influência da aplicação de 4 doses de calcário calcítico e 4 de dolomítico no equilíbrio de bases num Latossolo Vermelho Escuro álico, de textura argilosa. As 16 combinações entre $\mathrm{Ca}, \mathrm{Mg}$ e $\mathrm{K}$, onde o $\mathrm{K}$ foi fornecido através da adubação constante em todas as parcelas, mostraram forte antagonismo entre Ca e K, permitindo, com isso, aferir que a relação Ca/K assegurou alta produtividade, enquanto as relações $\mathrm{Ca} / \mathrm{Mg}$ e $\mathrm{Mg} / \mathrm{K}$ não se mostraram importantes com relação à produtividade. 
13.

3. MATERIAL E METODOS

O presente trabalho foi conduzido no sítio Boa Vista, Bairro Boa Vista, no munićpio de Pirassununga (SP), de propriedade do Sr. José Irineu Rosolen.

\subsection{Solo}

o pomar está instalado em um Latossolo Vermelho Escuro, textura média, distrófico (LEd).

Em 10 de julho de 1990 , para efeito de caracterização inicial do solo, foi efetuada analise química, conforme apresentado na Tabela 1.

Tabela 1. Resultados da análise química do solo em três profundidades (RAIJ \& QUAGGIO, 1983).

\begin{tabular}{|c|c|c|c|c|c|c|c|c|c|c|c|c|}
\hline Prof. & $\mathrm{pH}$ & M.O. & P & $\mathbf{K}$ & $\mathrm{Ca}$ & Mg & Al & $\mathrm{H}+\mathrm{Al}$ & SB & $T$ & & $\mathbf{m}$ \\
\hline$(\mathrm{cm})$ & $\mathrm{CaCl}_{2}$ & $\%$ & $\mathrm{\mu g} / \mathrm{cm}^{3}$ & & & meq & $/ 100 c$ & & & & $\%$ & \\
\hline $\begin{array}{l}00-20 \\
21-40 \\
41-60\end{array}$ & $\begin{array}{l}4,7 \\
4,9 \\
4,9\end{array}$ & $\begin{array}{l}1,9 \\
1,8 \\
1,6\end{array}$ & $\begin{array}{r}31 \\
9 \\
4\end{array}$ & $\begin{array}{l}0,60 \\
0,46 \\
0,38\end{array}$ & $\begin{array}{l}4,37 \\
3,39 \\
2,41\end{array}$ & $\begin{array}{l}0,76 \\
0,87 \\
0,65\end{array}$ & $\begin{array}{l}0,82 \\
0,22 \\
0,16\end{array}$ & $\begin{array}{l}8,0 \\
5,2 \\
3,4\end{array}$ & $\begin{array}{l}5,73 \\
4,72 \\
3,44\end{array}$ & $\begin{array}{r}13,73 \\
9,92 \\
6,84\end{array}$ & $\begin{array}{l}42 \\
48 \\
50\end{array}$ & $\begin{array}{r}13 \\
4 \\
4\end{array}$ \\
\hline
\end{tabular}


3.2. Características do pomar

o pomar que teve seu plantio realizado em setembro de 1987, possue como copa a variedade Pera (Citrus sinensis (L.) Osbeck) e como porta-enxerto o limão Cravo (Citrus limonia osbeck). O espaçamento utilizado foi de $4,0 \mathrm{x}$ $7,0 \mathrm{~m}$.

\subsection{Tratamentos}

Utilizando-se de diferentes produtos e misturas deles, visando elevar o valor de saturação por bases (V\%) para 70 (setenta), obteve-se a composição dos tratamentos apresentada na Tabela 2 .

Tabela 2. Caracterização dos tratamentos testados em pomar de laranja Pera no Sítio Boa Vista, Pirassununga (SP).

\begin{tabular}{cl}
\hline TRATAMENTO & \multicolumn{1}{c}{ CARACTERIZ̈AÇÃC } \\
\hline T & Testeminha \\
CC & Colcário calcítico \\
$C M$ & Calcário magnesiano \\
$C D$ & Calcário dolomítico \\
$C D 70+G 30$ & Calcário dolomítico + gesso \\
$M 25+C C 75$ & Magnesita $(25 \%)+$ calcário calcítico (75\%) \\
$M 15+C C 85$ & Magnesita $(15 \%)+$ calcário calcítico (85\%) \\
$M 15+G 85$ & Magnesita $(15 \%)+$ gesso $(85 \%)$ \\
& \\
\hline
\end{tabular}

$\mathrm{Na}$ Tabela 3 são apresentados os teores percentuais de CaO, Mgo e $S$, bem como os valores de PN e PRNT dos produtos e misturas utilizadas na composição dos tratamentos e, no Quadro 4, as dosagens utilizadas para elevar 
o valor de $V \%$ para 70 (setenta). Os tratamentos foram aplicados em 1990, sendo quant if icados de acordo com a análise química do solo (Tabela 1).

A aplicação dos tratamentos foi feita manualmente, distribuindo os corretivos em uma área de $12 \mathrm{~m}^{2}$ para cada árvore. Posteriormente foi efetuada a incorporação através de gradagem.

Tabela 3. Teores percentuais de CaO, MgO, S, PN e PRNT dos produtos e misturas utilizadas nos tratamentos.

\begin{tabular}{|c|c|c|c|c|c|}
\hline \multirow{2}{*}{ Produto } & $\mathrm{CaO}$ & MgO & $s$ & PN & PRNT \\
\hline & \multicolumn{5}{|c|}{$\%$} \\
\hline Calcário calcítico & 49,0 & 4,0 & - & 94 & 83,0 \\
\hline Calcário magnesiano & 39,0 & 12,0 & - & 91 & 76,0 \\
\hline Calcario dolomítico & 32,0 & 18,0 & - & 100 & 95,0 \\
\hline $\begin{array}{l}\text { Calcário dolomít ico }(70 \%) \\
+ \text { gesso }(30 \%)\end{array}$ & 40,0 & 15,0 & 5 & 100 & 95,0 \\
\hline Magnesita & 1,7 & 81,8 & - & 206 & 204,0 \\
\hline Gesso & 26,0 & - & 15,0 & - & - \\
\hline $\begin{array}{l}\text { Magnesita }(25 \%)+ \\
\text { Calcário calcítico }(75 \%)\end{array}$ & 37,2 & 23,5 & - & 122 & 113,0 \\
\hline $\begin{array}{l}\text { Magnesita }(15 \%)+ \\
\text { Calcário calcítico( } 85 \%)\end{array}$ & 41,9 & 15,7 & - & 111 & 101,1 \\
\hline $\begin{array}{l}\text { Magnesita }(15 \%)+ \\
\text { Gesso }(85 \%)\end{array}$ & 22,1 & 12,3 & 12,7 & 31 & 30,6 \\
\hline
\end{tabular}


Tabela 4. Dosagem dos produtos e misturas para elevar o valor de V\% para 70 (setenta), em cada um dos tratamentos.

\begin{tabular}{cccccc}
\hline \multirow{2}{*}{ Tratamento } & \multicolumn{2}{c}{ Dose } & CaO & MgO & S \\
& t/ha & $\mathrm{kg} / \mathrm{planta}$ & & $\mathrm{kg} / \mathrm{planta}$ & \\
\hline 1 & - & - & - & - & - \\
2 & 4,63 & 12,97 & 6,35 & 0,52 & - \\
3 & 5,06 & 14,16 & 5,52 & 1,70 & - \\
4 & 4,05 & 11,34 & 3,63 & 2,04 & - \\
5 & 4,05 & 11,34 & 4,54 & 1,70 & 0,57 \\
6 & 3,40 & 9,52 & 3,54 & 2,24 & - \\
7 & 3,80 & 10,64 & 4,46 & 1,67 & - \\
8 & 12,56 & 35,20 & 7,74 & 4,33 & 4,47 \\
\hline
\end{tabular}

3.4. Delineamento e análise estatística

0 delineamento experimental foi o de blocos casualizados, com 5 (cinco) repetições, totalizando 40 (quarenta) parcelas. Os tratamentos foram aplicados em parcelas com 5 plantas úteis, separadas por linhas de plantas bordadura. As medias foram comparadas pelo teste de Tukey ao nível de $5 \%$ de probabilidade (PIMENTEL GOMES, 1985).

\subsection{Tratos culturais}

As adubações em cobertura para os anos agrícolas $1990 / 91,1991 / 92$ e 1992/93, foram efetuadas na projeção da copa, com leve incorporação ao solo mediante gradagem, em tres aplicaçóes no período chuvoso, de outubro a fevereiro, 
17.

estimando-se uma produção de 3 caixas por planta para o ano agrícola $90 / 91$ e 5 caixas por planta para os anos $91 / 92$ e 92/93. As doses de fertilizantes furam calculadas em função da análise química do solo e la recomendação do GRUPO PAULISTA DE ADUBAÇÃO E CALAG LM PARA CITROS (1988), conforme apresentadas na Tabela 1 .

No mesmo período chuvoso de cada ano agrícola foram efetuadas 3 (três) adubaçôes foliares, sendo utilizados $7,5 \mathrm{~kg}$ de uréia; $4,5 \mathrm{~kg}$ de $\mathrm{ZnSO}_{4} \cdot 7 \mathrm{H}_{2} \mathrm{O} ; 3,0 \mathrm{~kg}$ de $\mathrm{MnSO}_{4} \cdot 4 \mathrm{H}_{2} \mathrm{O}$ e 1,2 kg de ácido bórico para 1500 litros de água, perfazendo, assim, uma solução com concentração de $0,5 \% \mathrm{~N}, 0,3 \% \mathrm{Zn}, 0,2 \%$ Mn e 0,08\% B (GRUPO PAULISTA DE ADUBAÇÃO E CALAGEM PARA CITROS, 1990). A aplicação foi feita na base de 101 itros de solução por planta no ano agrícola $90 / 91$ e 12 litros de solução por planta nos anos agrícolas $91 / 92$ e $92 / 93$.

Tabela 1. Esquema das adubações em cobertura realizadas nos três anos agrícolas.

\begin{tabular}{lccc}
\hline Ano agrícola & $\mathrm{N}$ & $\mathrm{P}_{2} \mathrm{O}_{5}$ & $\mathrm{~K}_{2} \mathrm{O}$ \\
& $-\mathrm{g} / \mathrm{planta}$ & & 0 \\
$1990 / 91$ & 470 & 80 & 300 \\
$1991 / 92$ & 670 & 0 & 300 \\
$1992 / 93$ & 670 & 0 & \\
\hline
\end{tabular}

Durante a condução do trabalho promoveu-se o controle das plantas daninhas através de roçadeira e, na época da colheita, fez-se a capina manual na área abaixo da copa, bem como a roçada nas entre-linhas. 
18.

A fim de evitar o ataque de formigas, foi aplicada manualmente, a cada dois meses, isca granulada nas parcelas onde haviam olheiros.

o controle fitossanitário foi feito frequentemente para controle de ácaros, da leprose e ferrugem, e verrugose.

3.6. Ava liações

3.6.1. Amostragens e análises foliares

As amostragens foliares foram realizadas segundo recomendação do GRUPO PAULISTA DE ADUBAÇÃO E CALAGEM PARA CITROS (1990) no mês de abril de 1991 e 1992, respectivamente referentes aos anos agrícolas $1990 / 91$ e $1991 / 92$ coletando-se a 3a e 4 a folhas, com idade de 5 a 7 meses, a partir do fruto com $1,0 \mathrm{~cm}$ de diametro. As fothas foram coletadas nas 5 plantas da parcela, em numero de oito folhas por planta, totalizando 40 folhas por parcela.

As amostras de folhas foram levadas para o Laboratório de Análise de plantas do Departamento de ciencia do So 10 (ESALQ/USP), onde foram lavadas com detergente e enxaguadas em água destilada e, em seguida, colocadas em papel absorvente. Posteriormente, foram colocadas em sacos de papel perfurados e postas a secar em estufa com circulação forçada de ar a $70^{\circ} \mathrm{C}$. Após secas, as folhas foram moidas em um micro moinho tipo wiley e peneiradas em peneiras de 20 mesh (MALAVOLTA et a $1 ., 1989$ ).

Após a digestão sulfúrica, foi determinado o teor foliar do $\mathrm{N}$ pelo semi-micro Kjeldahl (SARRUGE \& HAAG, 1974). Através da digestão nítrico-perclórica determinaram-se os teores de $\mathrm{K}, \mathrm{Ca}, \mathrm{Mg}, \mathrm{Cu}, \mathrm{Fe}, \mathrm{Zn}$ e $\mathrm{Mn}$ pelo espectrofotômet ro de absorção atômica (BATAGLTA et a 1., 1983), o p por 
colorimetria do metavanadato (MALAvolta et al., 1989) e S por turbidimetria do sulfato de bario (VITTI, 1988).

Utilizando-se da digestão seca, o B foi determinado por colorimetria com o emprego da azometina $\mathrm{H}$, citado em MALAVOLTA et al., (1989).

\subsubsection{Amostragens e análise do solo}

As amostragens de solo foram realizadas em julho de 1990 e em maio de 1991 (ano agrícola 1990/91) e de 1992 (ano agrícola 1991/92), em três profundidades $(0-20 \mathrm{~cm}, 21-40 \mathrm{~cm}$ e $41-$ $60 \mathrm{~cm})$, na projeção da copa. Em cada parcela retiraram-se 5 amostras simples para cada profundidade.

As determinações químicas foram efetuadas no Laboratório de Análises de Solos do Departamento de Ciência do Solo (ESALQ/USP), onde inicialmente as amostras foram secas ao ar para posterior análise de rotina (RAIJ \& QUAGGIO, 1983), a lumínio trocável (RAI \& ZULLO, 1977) e S-SO ${ }_{4}^{-}$(VITTI, 1989).

\subsubsection{Produção}

As colheitas das safras $91 / 92$ e $92 / 93$ ocorreram no mes de setembro de 1991 e de 1992 , respectivamente, quando os frutos de cada parcela foram acondicionados em caixas plásticas de colheita para posterior pesagem.

No ato da colheita foi efetuada a amostragem dos frutos, quando eram tomados ao acaso 2 frutos de cada planta, totalizando, assim, dez frutos por parcela, os quais foram utilizados para a análise tecnológica do suco e caracterização dos frutos. 
20.

3.6.4. Características dos frutos

Os dez frutos amostrados em cada parcela, na ocasião da colheita, tiveram seus diâmetros e comprimentos nedidos mediante a utilização de um paquímetro.

Para a avaliação do peso dos frutos utilizou-se uma balança graduada com divisões mínimas de dez gramas, sendo o resultado expresso em peso médio ( $\mathrm{g}$ ) dos frutos.

\subsubsection{Análise tecnologica}

Com auxílio de um espremedor elétrico, extraiuse o suco dos dez frutos para análise de sólidos solúveis (Brix) e acidez.

- teor de solidos solúveis foi avaliado com o auxílio de um refratômetro de campo, utilizando-se uma gota do suco extraído (MENDES, 1976).

Para determinação da acidez empregou-se o método de titulação com $\mathrm{NaOH}$ a $0,1 \mathrm{~N}$, sendo o seu valor calculado mediante o uso da seguinte fórmula:

$$
\text { Acidez }=\frac{0,64 \times \mathrm{ml} \text { soda }}{\mathrm{ml} \text { suco }(20 \mathrm{ml})+1 / 10 \text { brix livre }}
$$

Com a análise do brix livre e da acidez corrigida pode-se determinar o "Ratio", utilizando-se da seguinte fórmula:

$$
\text { "Ratio" }=\frac{\text { brix livre }}{\text { acidez corrigida }}
$$




\section{RESULTADOS E DISCUSSAO}

\subsection{Análise química do solo}

4.1.1. Ano agrícola $1990 / 91$

Nas Tabelas 5,6 e 7 estão apresentados os resultados médios das características químicas das amostras de solo relativos ao ano agrícola $1990 / 91$ para as profundidades $0-20 \mathrm{~cm}, 21-40 \mathrm{~cm}$ e $41-60 \mathrm{~cm}$, respect ivamente. Examinando esses resultados, observa-se que, nas três profundidades estudadas, - pH apresentou elevaça para todos os tratamentos com aplicação de corretivos em relação à testemunha, como já haviam relatado MALAVOLTA et a 1. (1986) e LOPES (1989).

Para o elemento $P$, o tratamento com magnesita (25\%) + calcário calcítico $(75 \%)$, na profundidade $0-20 \mathrm{~cm}$, proporcionou aumento significativo. Já na profundidade $41-60 \mathrm{~cm}$ coube aos tratamentos 7 e 8 , os quais apresentam a magnesita em suas composições, os maiores teores de $P$.

Foi verificado um gradiente crescente no teor de $\mathrm{S}-\mathrm{SO}_{4}$ da profundidade $0-20 \mathrm{~cm}$ para a $41-60 \mathrm{~cm}$. Nos tratamentos CD70 + G30 e M15 + G85, onde ocorrem a presença do gesso, houve uma maior percolação de $\mathrm{S}-\mathrm{SO}_{4}$ para as camadas mais profundas do solo, conforme já verificado por couTo et al (1979) e SOUZA \& 
RITCHEY (1986). Pelo fato do tratamento M15+G85 apresentar uma maior quantidade de gesso na sua composição, o teor de $\mathrm{S}-\mathrm{SO}_{4}$ foi significativamente superior aos demais nas três profundidades estudadas.

A adubação em cobertura com cloreto de potássio (KCl), foi a única fonte de potássio para todos os tratamentos. $\mathrm{Na}$ profundidade $0-20 \mathrm{~cm}$, observa-se que o teor de $\mathrm{K}$ para 0 tratamento M15 + G85 foi o mais baixo, diferindo significativamente dos demais. por outro lado, esse tratamento apresentou o maior teor de $\mathrm{K}\left(0,40 \mathrm{meq} / 100 \mathrm{~cm}^{3}\right)$ na profundidade $21-40 \mathrm{~cm}$, mostrando, assim, que o gesso pode lixiviar o potássio para camada mais profunda que a superficial (RITCHEY et al., 1981; QUAGGIO et a 1., 1982; ROSOLEM \& MACHADO, 1984; DAL Bo, 1985).

Os teores de cálcio no solo tiveram aumentos através da aplicação dos corretivos. o cálcio absorvido pelas plantas na camada superficial do solo corrigido ou presente na parte aérea das plantas não é translocado para as extremidades das raízes em crescimento (MENGEL \& KIRKBY, 1982). Verificando - comportamento do tratamento M15 + G85, observa-se que o teor de cálcio na profundidade $41-60 \mathrm{~cm}$ é significativamente superior aos demais tratamentos, com exceção do M15 + CC85 e praticamente 0 mesmo apresentado, por este tratamento, na camada $0-20 \mathrm{~cm}$. Sendo $O$ gesso a única fonte de $\mathrm{Ca}$ no tratamento, abribui-se a ele a responsabilidade do aumento da concentração de Ca no subsolo (RITCHEY et al. 1980; PAVAN et a 1., 1984; HAMMEL et a 1., 1985; SUMNER et al., 1986; CHAVES et a l., 1988; FARINA \& CHANNON, 1988a).

Os tratamentos M $25+\operatorname{CC} 75$ e M15 + CC 85 , os qua is apresentam a magnesita $(81,8 \%$ de $M g O)$ em suas composições, possibilitaram juntamente com o tratamento $\mathrm{CM}$, os maiores teores de magnésio na camada $0-20 \mathrm{~cm}$, entretanto esses teores não diferiram significativamente dos tratamentos CD70 + G30 e M15 + G85. Na camada $21-40 \mathrm{~cm}$, os tratamentos M25 + CC75 e M15 
+ G85 tiveram os teores de magnésio estatisticamente iguais aos tratamentos CM e M15 + CC85. Por outro lado, na camada 41$60 \mathrm{~cm}$, o tratamento $M 15+G 85$ foi significativamente superior aos demais tratamentos, comprovando, conforme RITCHEY et al. (1981) e QUAGGIo et al. (1982), que o gesso, em maior dosagem nesse tratamento, promove a movimentação do $\mathrm{Mg}$ para camadas mais profundas.

A aplicação dos tratamentos não afetou o teor de alumínio em relação a testemunha, em qualquer das profundidades. Quando da anal ise da acidez potencial $(H+A 1)$, verificaram-se os maiores teores absolutos, nas três profundidades, para a testemunha, evidenciando que o uso de corretivos é prática indispensável e suficiente para a correção deste tipo de acidez, aumentando, assim, 0 V\% e reduzindo a saturação por alumínio (VITTI \& DONADIo, 1988). Essa afirmativa pode ser constatada pelos valores do $\mathrm{V} \%$, pois ocorreu um aumento significativo nos tratamentos onde foram aplicados corretivos em relação a testemunha para as três profundidades em estudo. O mesmo efeito foi verificado na saturação por alumínio, ou seja, a aplicação de corretivos afetou diretamente o valor $\mathrm{m}$, de maneira a reduzir seus valores quando comparados com a testemunha.

Ressalta-se para as profundidades $21-40 \mathrm{~cm}$ e $41-$ $60 \mathrm{~cm}$, os maiores valores de $\mathrm{V} \%$ e os menores de $\mathrm{m} \%$ para 0 tratamento M15 + G85, demonstrando a grande eficácia do gesso no controle da saturação por alumínio e consequente aumento nos pontos de troca de cátions no complexo coloidal do solo. (PAVAN et al., 1982).

Para a soma de bases na camada $0-20 \mathrm{~cm}$ o tratamento M15 + CC85 diferiu significativamente dos tratamentos $T, C C$ e $C D$. Entretanto, na profundidade $21-40 \mathrm{~cm} \circ$ tratamento M15 + G85 foi superior somente a testemunha e na profundidade $41-60 \mathrm{~cm}$ esse tratamento apresentou valor maior que os demais, com exceção do tratamento M15 + CC85. 


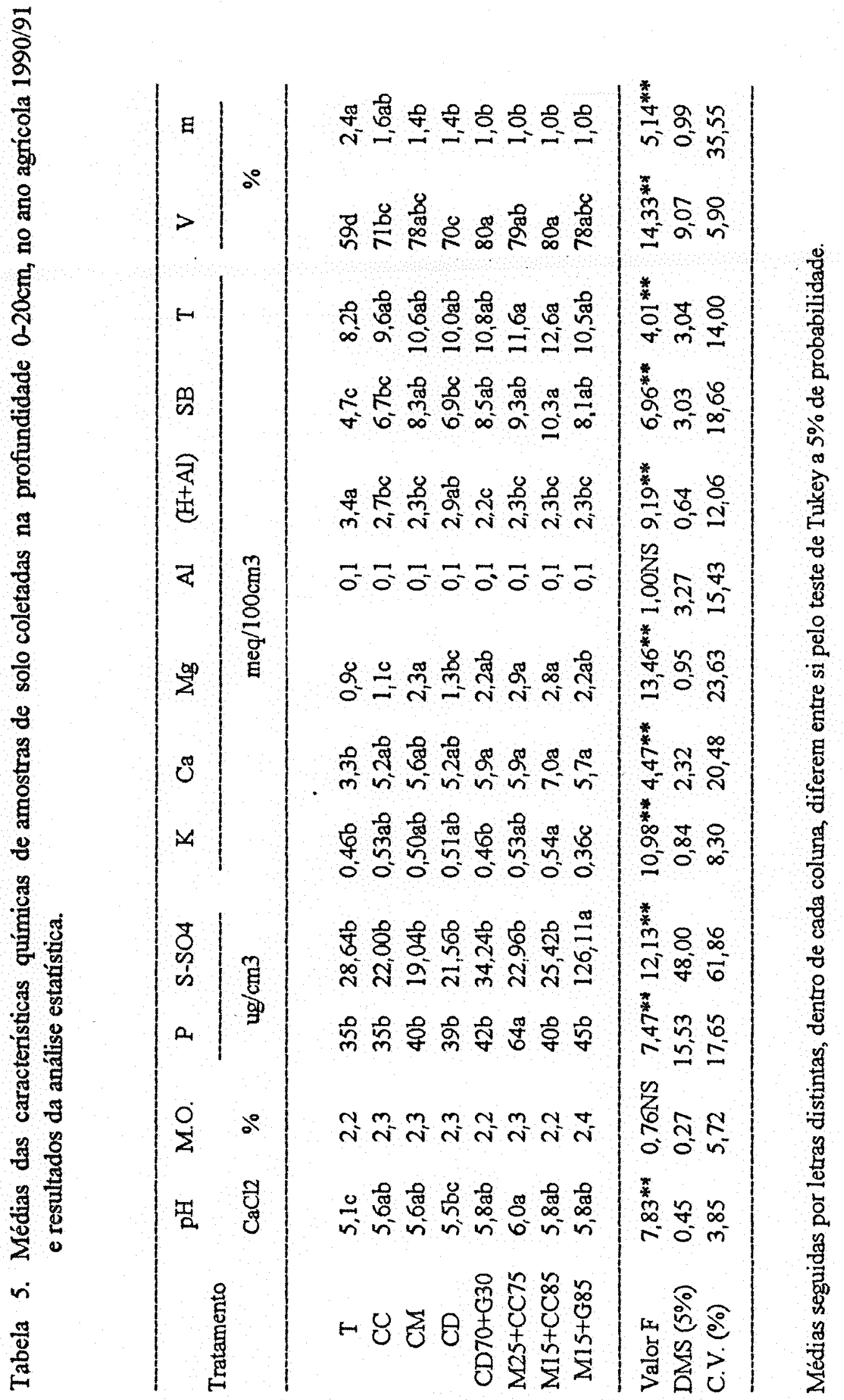




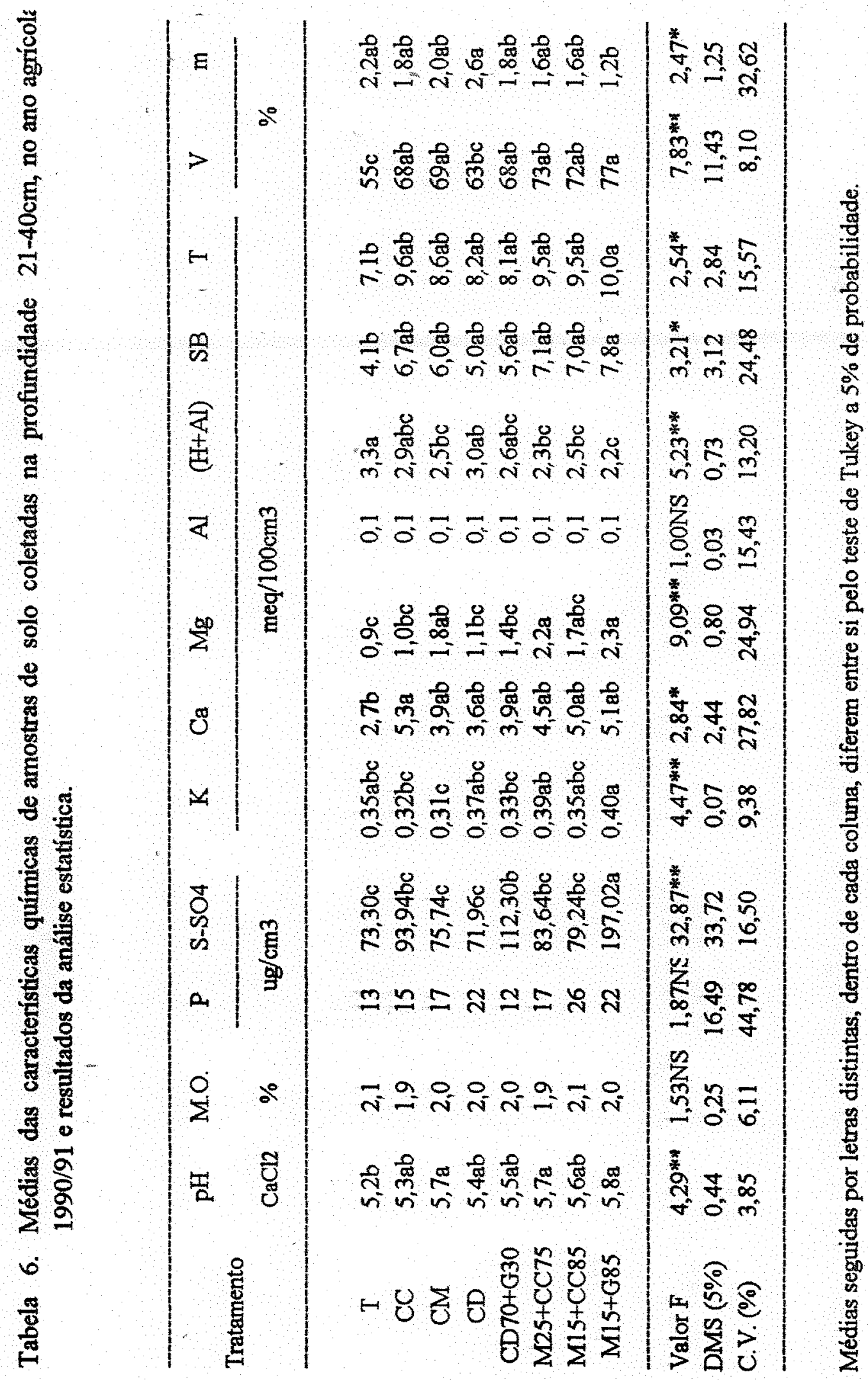




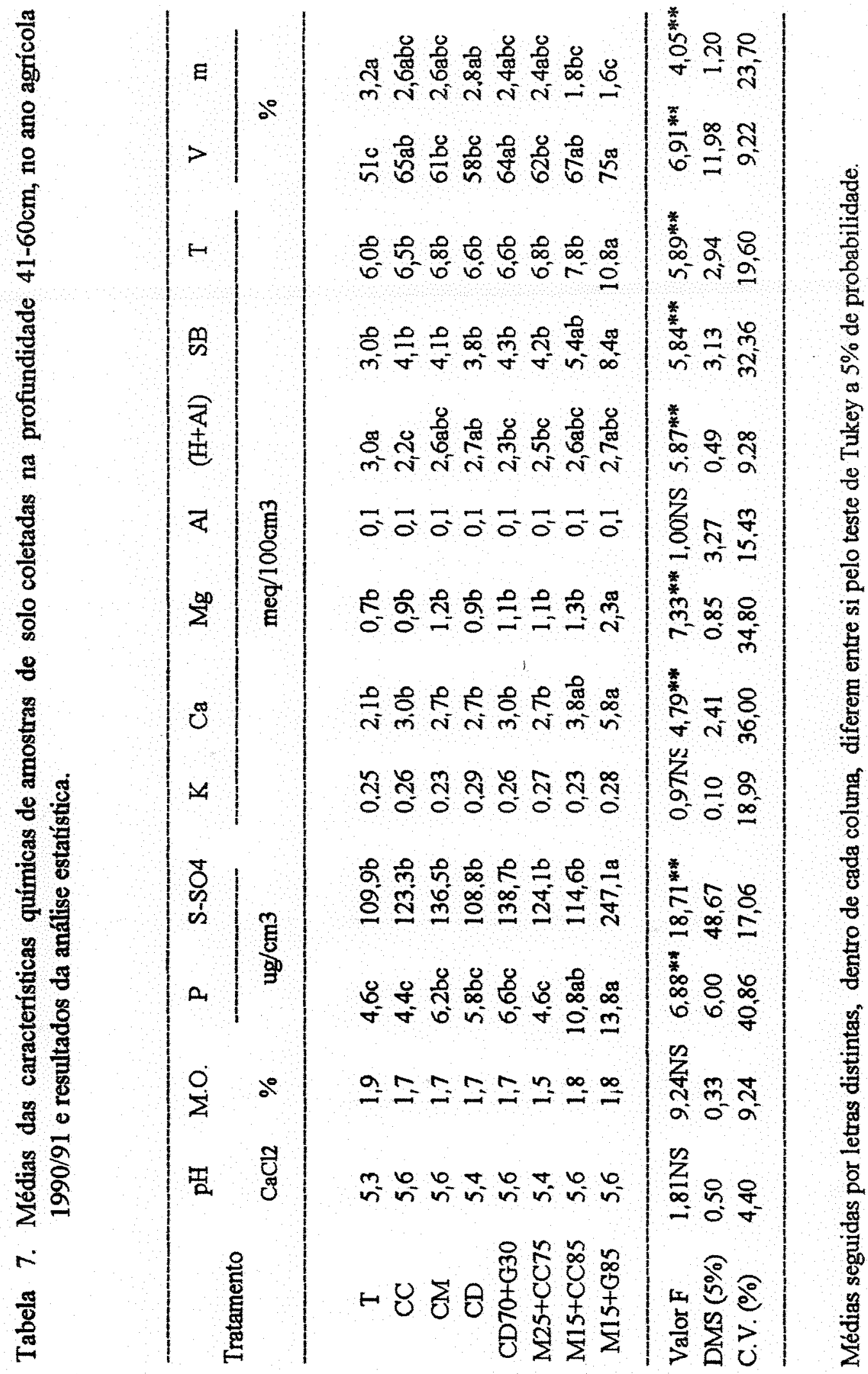


Os tratamentos compostos pela combinação da magnesita com calcário calcítico (M25+CC75 e M15+CC85) tiveram seus valores de CTC superiores ao tratamento testemunha, na camada $0-20 \mathrm{~cm}$. Na camada $21-40 \mathrm{~cm}$ foi o tratamento M15+G85 que diferiu significativamente da testemunha, e na camada $41-60 \mathrm{~cm}$ o referido tratamento apresentou o valor de CTC superior aos demais tratamentos.

$\mathrm{Na}$ camada $0-20 \mathrm{~cm}$, os tratamentos que tiveram aplicação de corretivos apresentaram os valores de V\% superiores a testemunha, enquanto na camada $21-40 \mathrm{~cm} 0$ tratamento CD não diferiu da testemunha. Para a camada $41-60 \mathrm{~cm}$, coube à testemunha o menor (51\%) e ao tratamento M15+G85o maior $(75 \%)$ valor absoluto.

As relações entre bases do solo, nas profundidades $0-20 \mathrm{~cm}, 21-40 \mathrm{~cm}$ e $41-60 \mathrm{~cm}$, estão apresentadas na Tabela 8.. QUAGGIO et al. (1992) relataram que, no caso da citricultura, existem recomendacooes técnicas para ajustar a relação $\mathrm{Ca} / \mathrm{Mg}$ para valores entre 3 e 4 . Com isso, somente os tratamentos $T$ e $C D$, na profundidade $0-20 \mathrm{~cm}$, estão enquadrados nessa faixa. Já para a profundidade $21-40 \mathrm{~cm}$ os tratamentos CD e M15 + CC85 apresentam valores da relação na faixa indicada, enquanto isso ocorre na profundidade $41-60 \mathrm{~cm}$, para essa relação, os tratamentos $T, C C$ e CD. O tratamento CC apresentou a maior relação $\mathrm{Ca} / \mathrm{Mg}$ nas duas camadas superiores. Entretanto, na camada 41-60 cm esse tratamento foi superior somente ao trat amento $\mathrm{CM}$.

A faixa ideal para a relação Ca/K está compreendida segundo RITCHEY et al. (1980), entre 9 e 25 . Desta forma, nas três profundidades, todos os tratamentos, com exceção da testemunha, apresentaram-se dentro do ideal. Nas profundidades, $0-20$ e 41-60 cm, coube ao tratamento $M 15+685$ a maior relação $\mathrm{Ca} / \mathrm{K}$, a qual não diferiu significativamente dos tratamentos $\operatorname{CD} 70+\mathrm{G} 30$ e M15+CC85 para a primeira 
28.

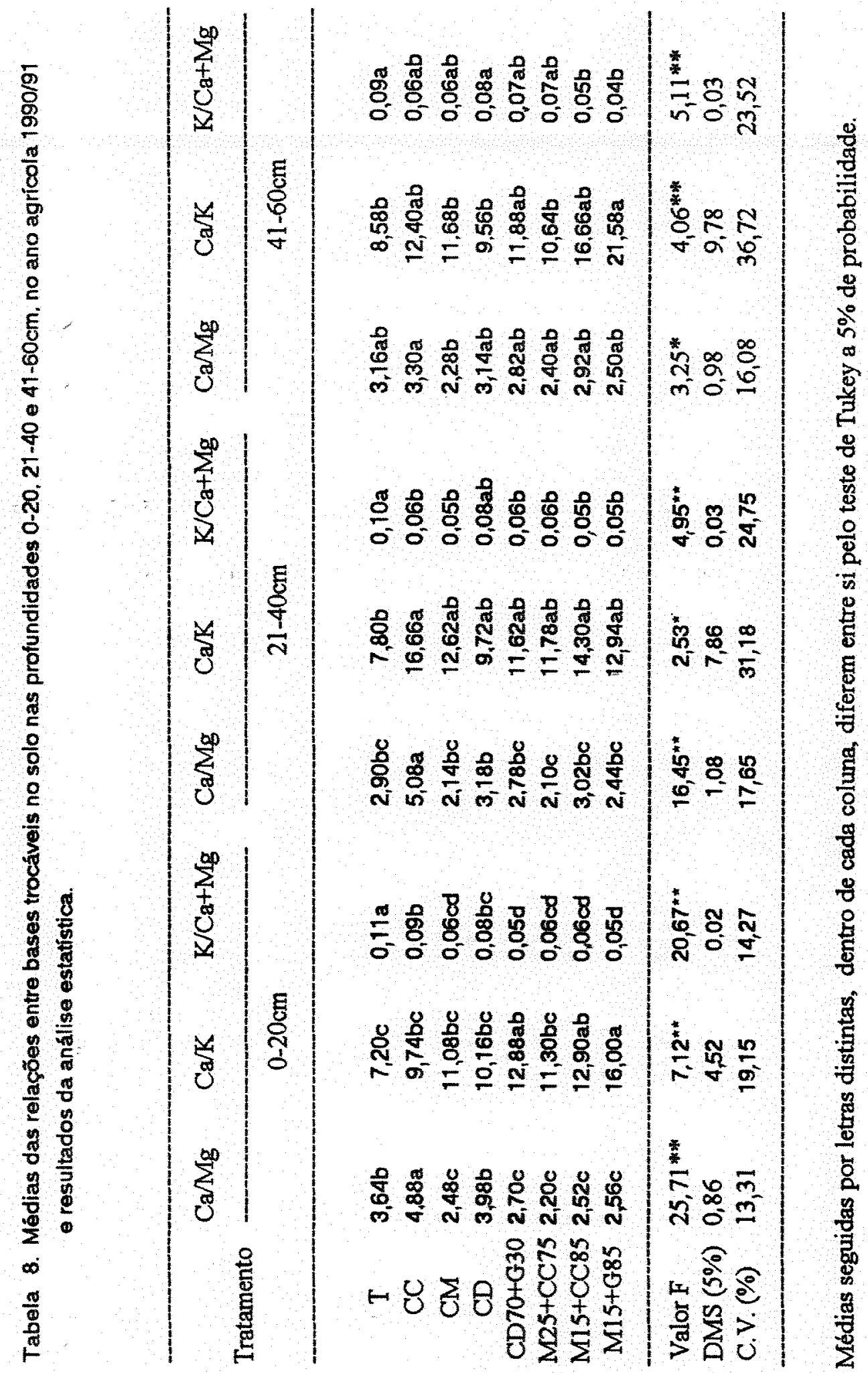


profundidade e os tratamentos CC, CD70+G30 e M15+CC85 para a segunda. Na profundidade $21-40 \mathrm{~cm}$, somente o tratamento CC foi superior a testemunha.

VITTI \& DONADIO (1988) atribuiram os valores entre 0,03 a 0,08 como os ideais para as relações $\mathrm{K} / \mathrm{Ca}+\mathrm{Mg}$, atribuindo o valor 0,06 como a relação ideal para citros. os maiores valores desta relą̧̃o foram verificados no tratamento testemunha, uma vez que não houve fornecimento de $\mathrm{Ca} e \mathrm{Mg}, \mathrm{e}$ foram de $0,11,0,10$ e 0,09 para as profundidades $0-20,21-40$ e $41-60 \mathrm{~cm}$, respectivamente.

\subsubsection{Ano agrícola 1991/92}

Nas Tabelas 9,10 e 11 são apresentados os resultados das características químicas do solo nas profundidades $0-20,21-40$ e $41-60 \mathrm{~cm}$, respectivamente, no ano agrícola $91 / 92$.

De acordo com QUAGGIO (1982), as condi ções serão ideais para o desenvolvimento dos citros quando o pH em $\mathrm{CaCl}_{2}$ estiver em torno de 5,5. Analisando os valores do $p H$ na profundidade $0-20 \mathrm{~cm}$, observa-se que os tratamentos que receberam corretivos diferiram significativamente da testemunha e apresentaram-se, com exceção do tratamento CC, em torno do pH adequado. Na profundidade $21-40 \mathrm{~cm}$, a testemunha apresentou valores que não diferiram significativamente dos tratamentos CC e $C D$, enquanto que, na profundidade $41-60 \mathrm{~cm}$, a testemunha não diferiu dos valores de $\mathrm{pH}$ dos tratamentos $\mathrm{CC}, \mathrm{CM}, \mathrm{CD}$ e $15+$ Cc85.

A aplicação de calcário magnesiano propiciou maiores teores de matéria orgânica nas três profundidades estudadas, sendo que apenas nas duas camadas superiores houve diferença significativa. Na cada de $0-20 \mathrm{~cm}$ o tratamento CM foi significativamente superior aos tratamentos $T$ e $M 15+685$, enquanto na camada de $21-40 \mathrm{~cm}$ foi superior ao tratamento $T$. 
30.

Os teores absolutos de fósforo, dos tratamentos onde se aplicaram corretivos, foram superiores ao da testemunha, comprovando que a elevação do $\mathrm{pH}$ aumenta a disponibilidade do elemento fósforo, MALAVOLTA et a 1. (1965). Entretanto, somente na camada $0-20 \mathrm{~cm}$ houve diferença significativa entre os tratamentos, onde somente os tratamentos M25 + CC85 e M15 + G85, na camada $0-20 \mathrm{~cm}$, foram superiores a testemunha.

De forma similar ao ano agrícola $90 / 91$, os teores de $\mathrm{S}-\mathrm{SO}_{4}$ tiveram o mesmo comportamento para o ano agrícola seguinte, ou seja, o tratamento com aplicação de magnesita + gesso diferiu significativamente dos demais tratamentos nas três profundidades, exceto na de $21-40 \mathrm{~cm}$, onde - tratamento com aplicação de calcário dolomítico + gesso não apresentou diferença significativa em relação ao tratamento M15 $+\mathrm{G} 85$.

Para os teores de $\mathrm{K}$ não se constataram diferenças significativas entre os tratamentos, nas três profundidades.

Os mais baixos teores de cálcio verificados na testemunha, em todas as profundidades estudadas, foi devida a não aplicação de corretivos na testemunha. Os maiores valores de cálcio na camada $0-20 \mathrm{~cm}$ foram verificados no tratamento onde se aplicou o calcário dolomítico $\left(6,5 \mathrm{meq} / 100 \mathrm{~cm}^{3}\right)$ e nos tratamentos com calcário calcitico isolado $\left(6,3 \mathrm{meq} / 100 \mathrm{~cm}^{3}\right)$ e conjugado a magnesita $\left(6,0\right.$ e $\left.5,2 \mathrm{meq} / 100 \mathrm{~cm}^{3}\right)$.

Os corretivos que apresentaram a magnesita na sua composição foram responsáveis, na profundidade $0-20 \mathrm{~cm}$, pelos maiores teores de Mg, cabendo ao tratamento M25 + CC75, onde se tem a maior concentração de magnésio $(23,5 \%)$, o maior valor $\left(2,2 \mathrm{meq} / 100 \mathrm{~cm}^{3}\right)$, tendo esse tratamento não diferenciado significativamente do tratamento M15+CC 85 . Nas profundidades 21-40 e 41-60 cm, somente os tratamentos M25+CC75 e M15 + G85 apresentaram teores de $\mathrm{Mg}$ superiores a testemunha. 
31.

Enquanto a testemunha teve o teor de alumínio aumentado em comparação ao ano agrícola anterior, os tratamentos com a aplicaça de corretivos eliminaram esse elemento, mas três profundidades. 0 mesmo efeito foi verificado para a saturação de alumínio $(\mathrm{m} \%)$.

A testemunha apresentou maiores valores de acidez potencial (H + Al) em relação aos demais tratamentos, com exceção ao tratamento CC, na camada de $21-40 \mathrm{~cm}$. Na camada de 41-60 cm, somente os tratamentos CM, CD70+G30 e M25 + CC75 foram significativamente inferiores a testemunha.

Os valores de soma de bases dos tratamentos onde se aplicaram corretivos se mostraram superiores ao da testemunha, conforme se verifica na camada de $41-60 \mathrm{~cm}$. Na camada $0-20 \mathrm{~cm}$ os tratamentos $\mathrm{CM}$ e CD70+G30 não diferem significativamente de testemunha, enquanto na camada $21-40 \mathrm{~cm}$, somente o tratamento M15+G85 foi significativamente superior à testemunha. Em função da aplicação de gesso, em quantidade maior no tratamento M15+G85, houve a lixiviaça das bases para camadas subsuperficiais (QUAGGIO et al, 1982; ROSOLEM \& MACHADO, 1984 ).

Os tratamentos CC e CD na camada de $0-20 \mathrm{~cm}$, e os tratamentos CC e M15+G85, na camada de $21-40 \mathrm{~cm}$, tiveram aumento significativo na CTC calculada em comparação à testemunha. Na análise da camada $41-60 \mathrm{~cm}$, se observa que os tratamentos CC, CD, M15+CC85 e M15+G85 tiveram seus valores superiores ao da testemunha, cabendo ao tratamento M15+G85o maior valor absoluto $\left(8,3 \mathrm{meq} / 100 \mathrm{~cm}^{3}\right)$.

A aplicação combinada de gesso e calcário tem sido recomendada, pois o aumento do $\mathrm{pH}$ e da CTC efetiva da camada superficial do solo, ocasionado pelo calcário, faz com que a lixiviação de $K$ e de $M g$ seja reduzida (RITCHEY et a ., 1980; QUAGGIO et a 1., 1982; PAVAN et a 1., 1984). Com a aplicação do gesso combinado com a magnesita, pode-se verificar 


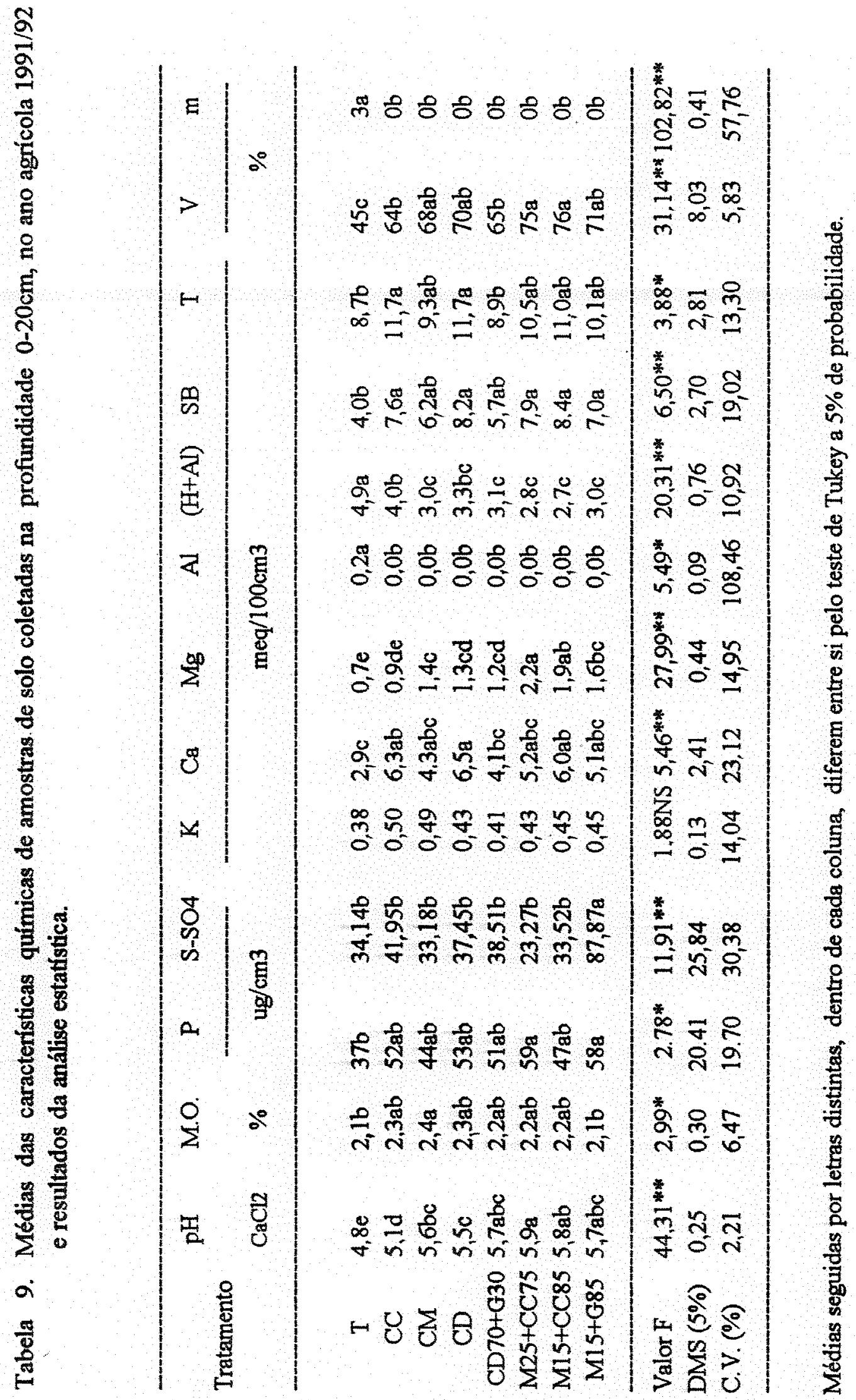




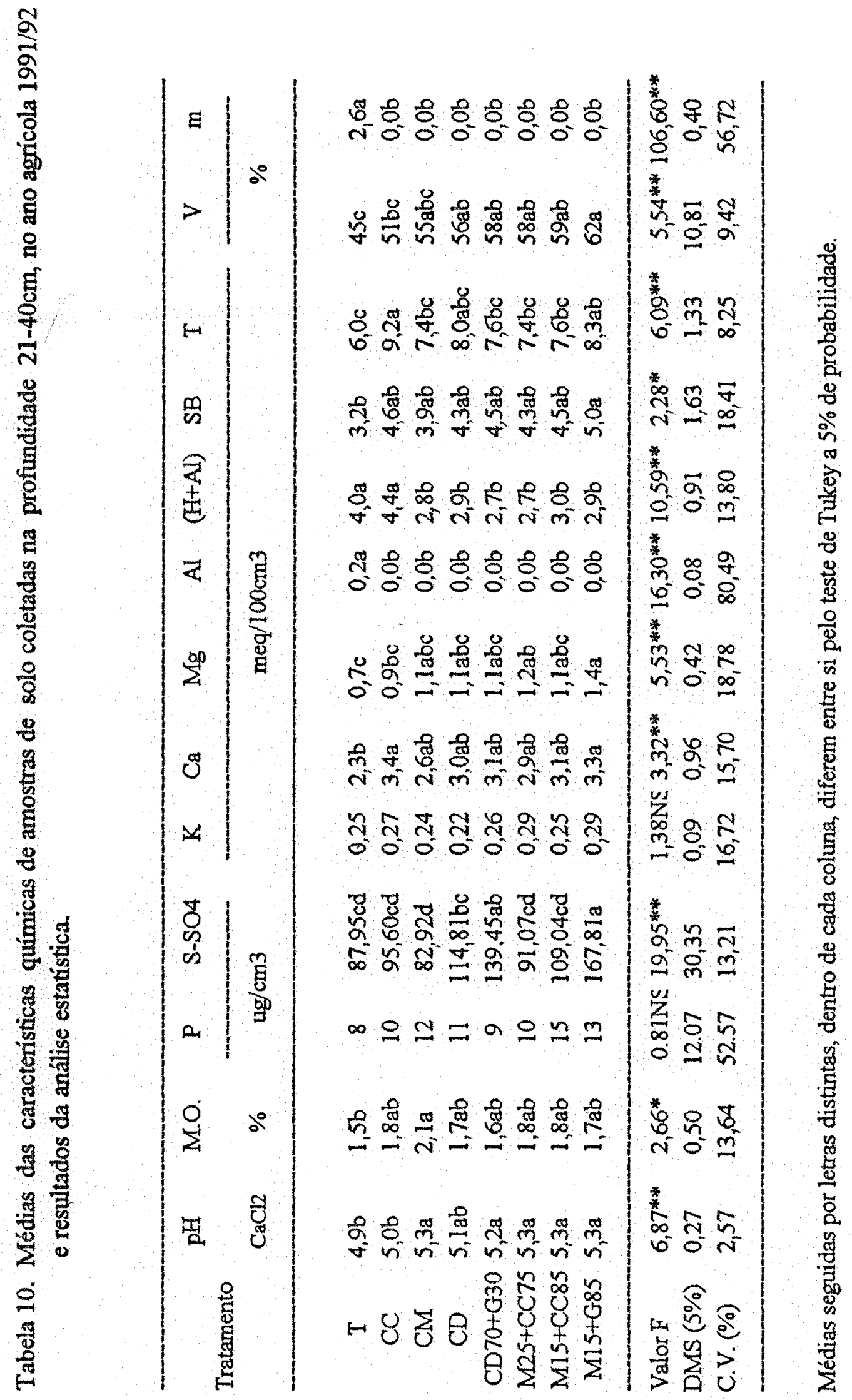


34.

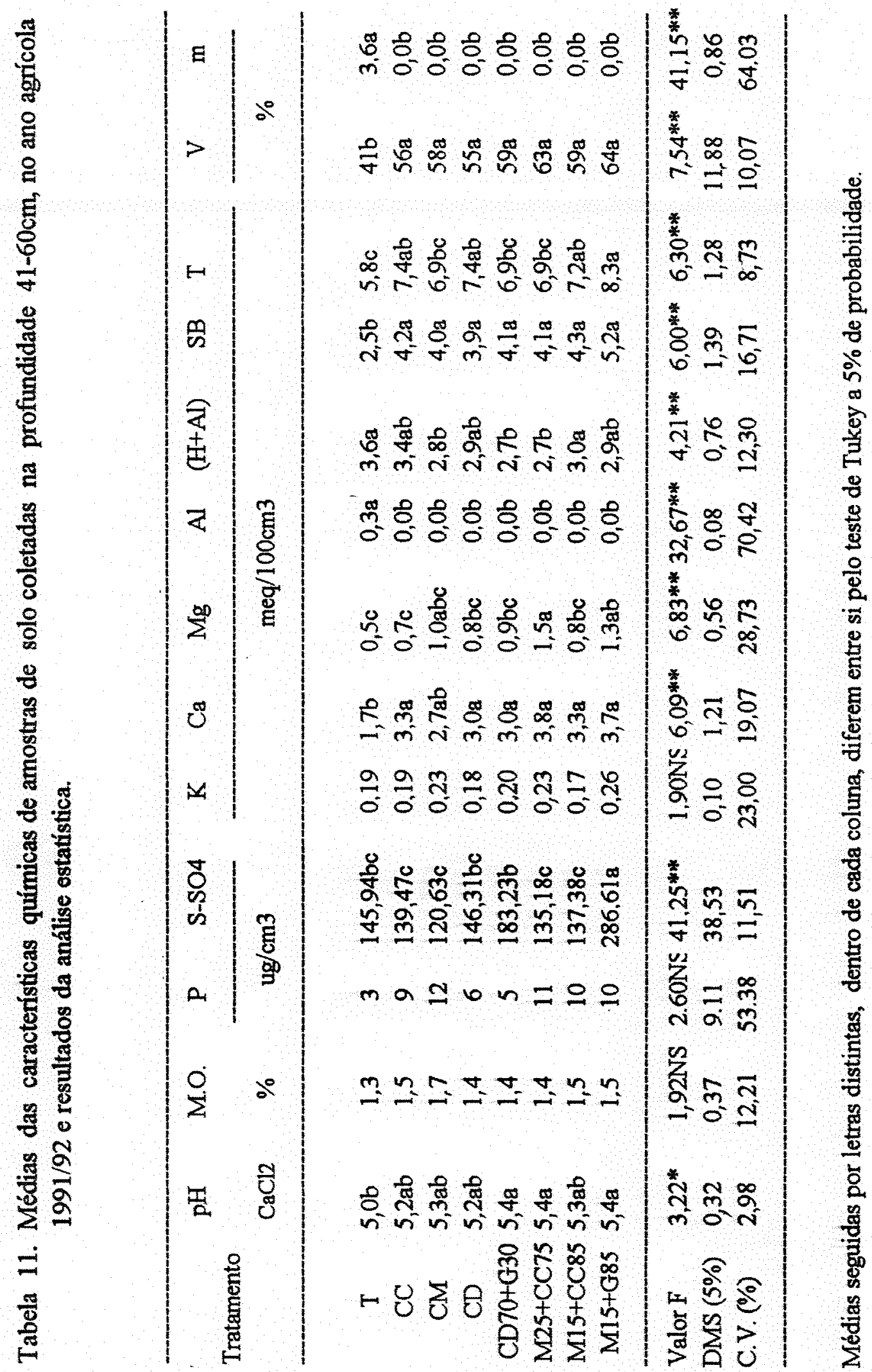


um aumento na CTC, bem como no $\mathrm{pH}$, aumentando a retenção de $\mathrm{K}$ e de $\mathrm{Mg}$.

Aumentos significativos nos valores de V\% foram a lcançados quando da aplicação dos corretivos em comparação à testemunha. Segundo GRUPO PAULISTA DE ADUBAÇÃO E CALAGEM PARA CITROS (1988) para valores abaixo de $60 \%$ na camada de $0-20 \mathrm{~cm}$ recomenda-se a calagem. Entretanto, para a referida camada, verifica-se que em todos os tratamentos, com exceção da testemunha, os valores estão acima deste valor. Nas profundidades $21-40 \mathrm{~cm}$ e $41-60 \mathrm{~cm}$, o tratamento com magnesita + gesso proporcionou os maiores valores absolutos de V, $62 \%$ e $64 \%$ respectivamente.

Estão demonstradas na Tabela 12 as relações entre bases trocáveis do solo, nas três profundidades estudadas. Analisando a relação $\mathrm{Ca} / \mathrm{Mg}$ nas três profundidades, observa-se que o tratamento CC foi significativamente superior aos demais tratamentos, exceto na profundidade $41-60 \mathrm{~cm}$, onde 0 citado tratamento foi superior aos tratamentos $T, C M$ e $M 15+$ G85. Esta maior relação é explicada pela alta concentração de CaO no calcário calcítico. Por outro lado, a menor relação $(2,36)$ coube ao tratamento $\mathrm{M} 25+\mathrm{CC} 75$, na profundidade $0-20 \mathrm{~cm}$, onde a mistura apresenta alta concentração de Mgo. A 1 ixiviação do Mg promovida pelo tratamento M15 + G85, em função da maior quantidade de gesso, pode ser responsável pela menor relação $\mathrm{Ca} / \mathrm{Mg}$ nas camadas $21-40$ e $41-60 \mathrm{~cm}$.

Nas profundidades $0-20$ e $21-40 \mathrm{~cm}$, coube ao tratamento $C D$ as maiores relações $C a / K$, no entanto essas relações só foram significativamente diferentes da testemunha. Para a profundidade $41-60 \mathrm{~cm}$, a relação do tratamento $M 25+\mathrm{Cc} 75$ foi superior aos tratamentos $T$ e CM. Todos os tratamentos encontram-se dentro da faixa ideal ( 9 a 25), exceto a testemunha na profundidade $0-20 \mathrm{~cm}$.

Para a relação $\mathrm{K} / \mathrm{Ca}+\mathrm{Mg}$, a testemunha teve seus valores acima da faixa ideal $(0,03$ a 0,08$)$, nas profundidades 


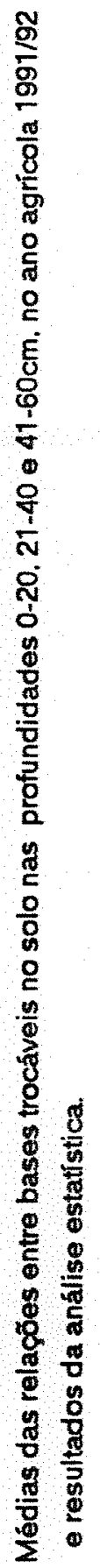

需

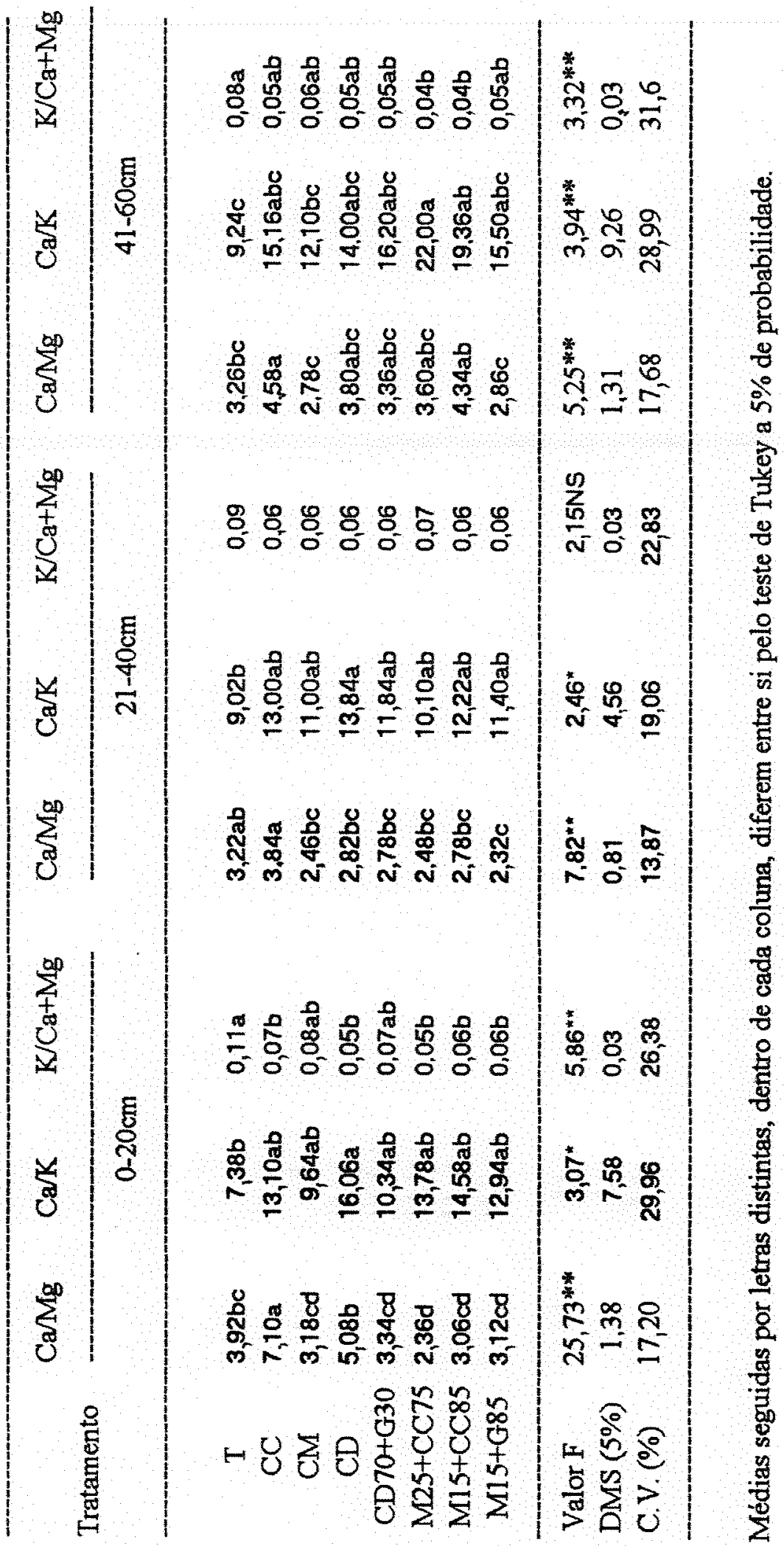

36. 
0-20 e 21-40cm, em decorrência do não fornecimento de fontes de $\mathrm{Ca}$ e de $\mathrm{Mg}$. Enquanto que nos demais tratamentos, os valores da relação se encontram dentro da faixa ideal, nas três profundidades. Observa-se também que em vários tratamentos se conseguiu obter o valor de 0,06 , ideal para citros (VITTI \& DONADIO, 1988$)$.

\subsection{Análise foliar}

\subsubsection{Ano agrícola $1990 / 91$}

Na Tabela 13 estão apresentados os teores de nutrientes das follhas geradas na primavera. As interpretações dos teores de macro e micronutrientes nas folhas de laranjeira foram feitas segundo classificação sugerida por GRUPO PAULISTA DE ADUBAÇÃo E CALAGEM PARA CITROS (1988).

Conforme os resultados, observa-se que os teores de $N$, mesmo havendo diferenças significativas entre os tratamentos, mostraram-se na faixa adequada para o citros. o tratamento $\mathrm{M} 15+\mathrm{CC} 85$ apresentou-se com teor deste nutriente superior estatisticamente ao da testemunha.

Para os elementos $P$ e Ca não foram verificadas diferenças significativas entre os tratamentos e os valores das concentraçoses destes nutrientes encontram-se altos na folha. A testemunha, mesmo não recebendo aplicação de corretivos e gesso, apresentou níveis altos de Ca na folha, indicando que o Ca nativo do solo ou aquele fornecido pela adubação foi suficiente para atender as necessidades da planta.

O maior teor de $K$ foi proporcionado pelo tratamento $C D 70+G 30$, diferenciando significativamente dos tratamentos T, CM, M25 + CC75 e M15 + CC85. Já para o elemento $\mathrm{Mg}$, o tratamento M15 + CC85 foi quem apresentou o maior valor absoluto para o teor desse nutriente, entretanto diferenciou significativamente somente do tratamento $\mathrm{CD}$. 
No tratamento M15 + cc85, o menor valor para o $\mathrm{K}(1,09 \%)$ correspondeu ao maior valor para o $\mathrm{Mg}(0,26 \%)$, podendo ser sugerido a causa deste efeito 0 antagonismo entre esses nutrientes, mas SOARES (1975) af irmou não haver nitidez no efeito antagônico entre as bases. Entretanto, DEJOU \& MONTARD (1982) observaram acentuado antagonismo entre Mg e K, onde a resposta positiva da adubação magnesiana foi anulada em presença do potássio.

A presença do gesso em maior dosagem no tratamento M15+G85 resultou no maior teor de $S$ nas folhas $(0,44 \%)$, diferindo significativamente dos demais tratamentos. Esse teor é qualificado como alto, enquanto aqueles dos demais tratamentos estão em nível adequado.

Os elementos $B$ e $\mathrm{Zn}$ encontram-se em concentrações adequadas, apesar das diferenças significativas nos teores do primeiro nutriente. Em relação ao elemento B, observa-se que o tratamento $\operatorname{CD} 70+$ G30 foi significativamente superior ao tratamento M15+G85.

Da mesma forma, os tratamentos com magnesita e - tratamento com calcario magnesiano propiciaram baixos teores de $\mathrm{Cu}$, que o tratamento com calcario calcítico.

o alto teor de Fe apresentado pelos tratamentos com gesso se deve ao aumento da absorção deste nutriente quando da aplicação deste produto no solo, pois segundo explicação sugerida por OLSEN \& WATANABE (1979), a formação do par iônico entre o cátion e o sulfato diminuem a atividade do $\mathrm{Fe}$ em solução, favorecendo o deslocamento do equilíbrio no solo, no sentido de liberar mais íons ( $F e$ ) para a solução, permitindo maior absorção pelas plantas.

Com relação ao nutriente manganês, os teores estavam em nível alto para todos os tratamentos, tendo o tratamento com calcário dolomítico + gesso apresentado o maior valor absoluto para esse teor ( $83 \mathrm{ppm})$. No entanto, esse 


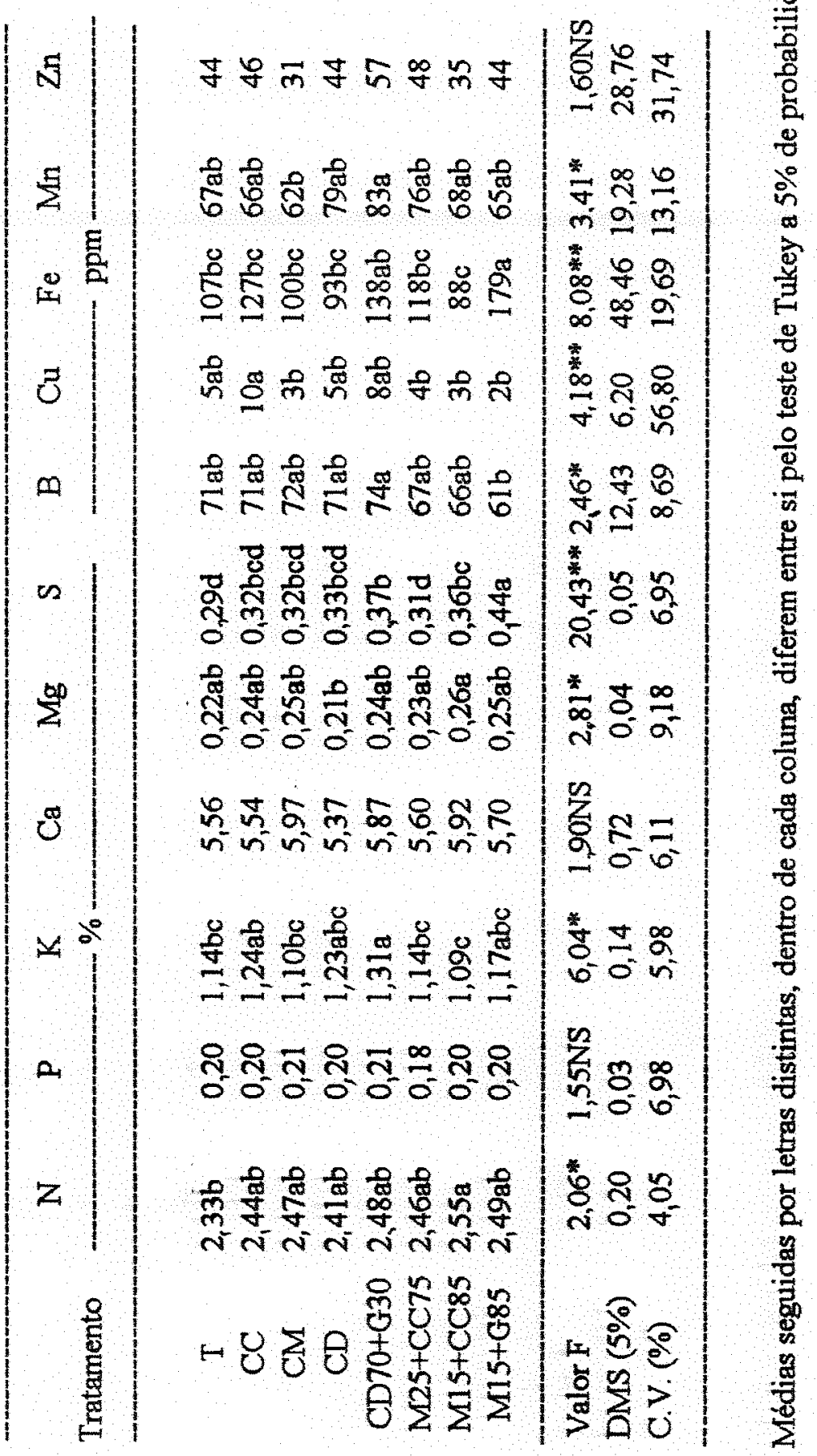




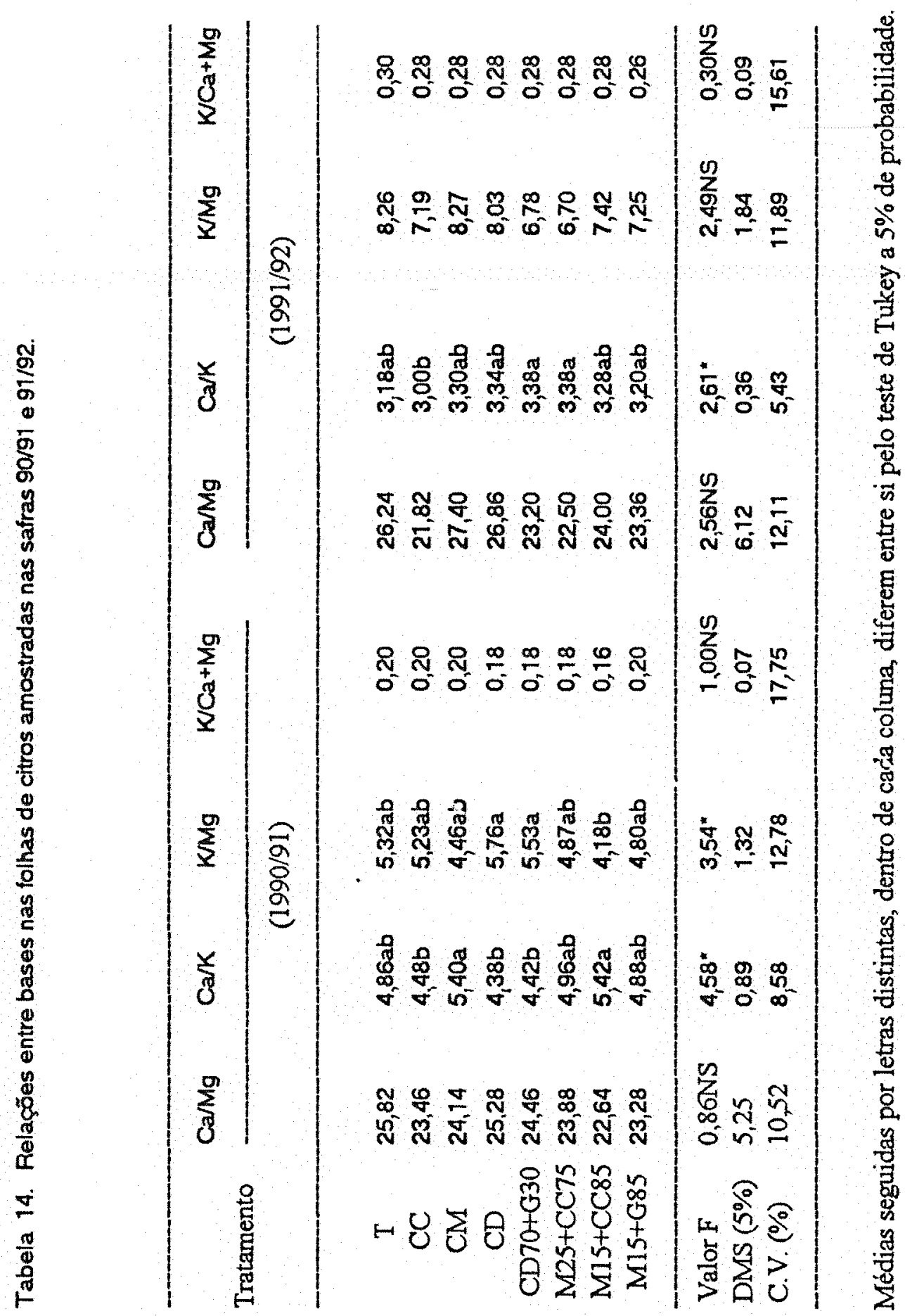


41.

tratamento só diferiu significativamente do tratamento com calcário magnesiano.

Na Tabela 14 estão relacionados os resultados das relações entre bases nas folhas de laranjeira pêra. Em decorrencia do al to teor de Ca nas forhas, a relação $\mathrm{Ca} / \mathrm{Mg}$ se mostrou muito superior a relação ideal para citros que é de 10 (MALAVOLTA, 1979). Da mesma forma, as relações Ca/K dos tratamentos estão acima da faixa ideal $(1,8$ a 4,5$)$. A relação $\mathrm{Ca} / \mathrm{K}$ na follha é menor que no solo, entretanto a folha absorve esses nutrientes em proporções diferentes daquelas existentes no solo, enquanto a relação $\mathrm{Ca} / \mathrm{Mg}$ é maior na folha, porém a planta absorve $\mathrm{Ca}$ e $\mathrm{Mg}$ na mesma proporção existente no solo (QUAGGIO et a 1., 1992).

A relação $\mathrm{K} / \mathrm{Mg}$ apresentou os tratamentos $\mathrm{CD}$ e $\mathrm{CD} 70$ + G30 significativamente superiores ao tratamento M15 + CC85. Essa diferença não pode ser explícada pelo teor de Mgo nos tratamentos, uma vez que existem tratamentos com teores maiores e menores aos tratamentos em questão.

\subsubsection{Ano agrícola $1991 / 92$}

Os teores de nutrientes das folhas geradas na primavera estão apresentadas na Tabela 15. Igualmente ao ano agrícola anterior, os teores dos nutrientes foram analisados segundo sugestão do GRUPO PAULISTA DE ADUBAÇÃo E CALAGEM PARA CITROS (1988).

Os níveis de nitrogênio estavam em padrões baixos em todos os tratamentos, tendo o tratamento com calcário calcítico apresentado significativamente o maior teor $(2,20 \%)$, em relação aos tratamentos com calcário magnesiano $(2,02 \%)$ e calcário dolomítico $(2,04 \%)$.

- teor de $P$ do tratamento $\operatorname{CD} 70+G 30$ foi superior ao do tratamento $\mathrm{CD}$, sendo que somente os tratamentos 
$\mathrm{CD} 70+\mathrm{G} 30, \mathrm{CC}, \mathrm{M} 25+\mathrm{CC} 75$ e $\mathrm{M} 15+\mathrm{G} 85$ apresentaram teores adequados de fósforo nas folhas.

A aplicação de calcário magnesiano e a testemunha foram responsáveis pelos teores mais altos de $K$ nas folhas do que o tratamento com calcário dolomítico + gesso. Entretanto, todos os tratamentos estavam em níveis adequados. As folhas amostradas em todos os tratamentos apresentaram teores altos de cálcio e baixos de magnésio. Foi observado que a redução dos teores de $\mathrm{Ca}$ do ano agrícola anterior para este ano foi paralela ao aumento nos teores de K. Isto pode ser explicado pelas manifestações antagônicas do cálcio sobre o potássio (BOWER \& PIERRE, 1944; YORK et al., $1953)$.

A maior concentração de enxofre no tratamento com magnesita e gesso, diferindo significativamente dos demais tratamentos comprova o suprimento adequado do nutriente $S$, na forma de gesso (VITTI et al., 1986).

Os micronutrientes B e Mn tiveram seus teores em níveis adequados para todos os tratamentos. Para os tratamentos $T, C M$ e $C D$, encontraram-se altos teores de $\mathrm{Cu}$ e excessivos teores de Fe. Já para o tratamento M15 + G85 juntamento com os tratamentos $\operatorname{CD} 30+\mathrm{G} 70$ e $M 15+\mathrm{CC} 85$, o teor de Fe foi menor que os tratamentos envolvendo aplicaça dos calcários ( $\mathrm{CC}, \mathrm{CM}$ e $\mathrm{CD}$ ) exclusivamente e na testemunha.

O maior teor de $\mathrm{Zn}$ foi proporcionado pelo tratamento $C D 70+G 30$, diferindo significativamente dos demais tratamentos, com exceção da testemunha. Entretanto, todos os tratamentos tem suas concentrações de $\mathrm{Zn}$ abaixo dos valores adequados.

As relações entre bases nas folhas da laranjeira Pêra no ano agrícola $91 / 92$ estão demonstradas na Tabela 14 , onde não foram observadas diferenças significativas entre os tratamentos nas relações $\mathrm{Ca} / \mathrm{Mg}, \mathrm{K} / \mathrm{Mg}$ e $\mathrm{K} / \mathrm{Ca}+\mathrm{Mg}$. 
43.
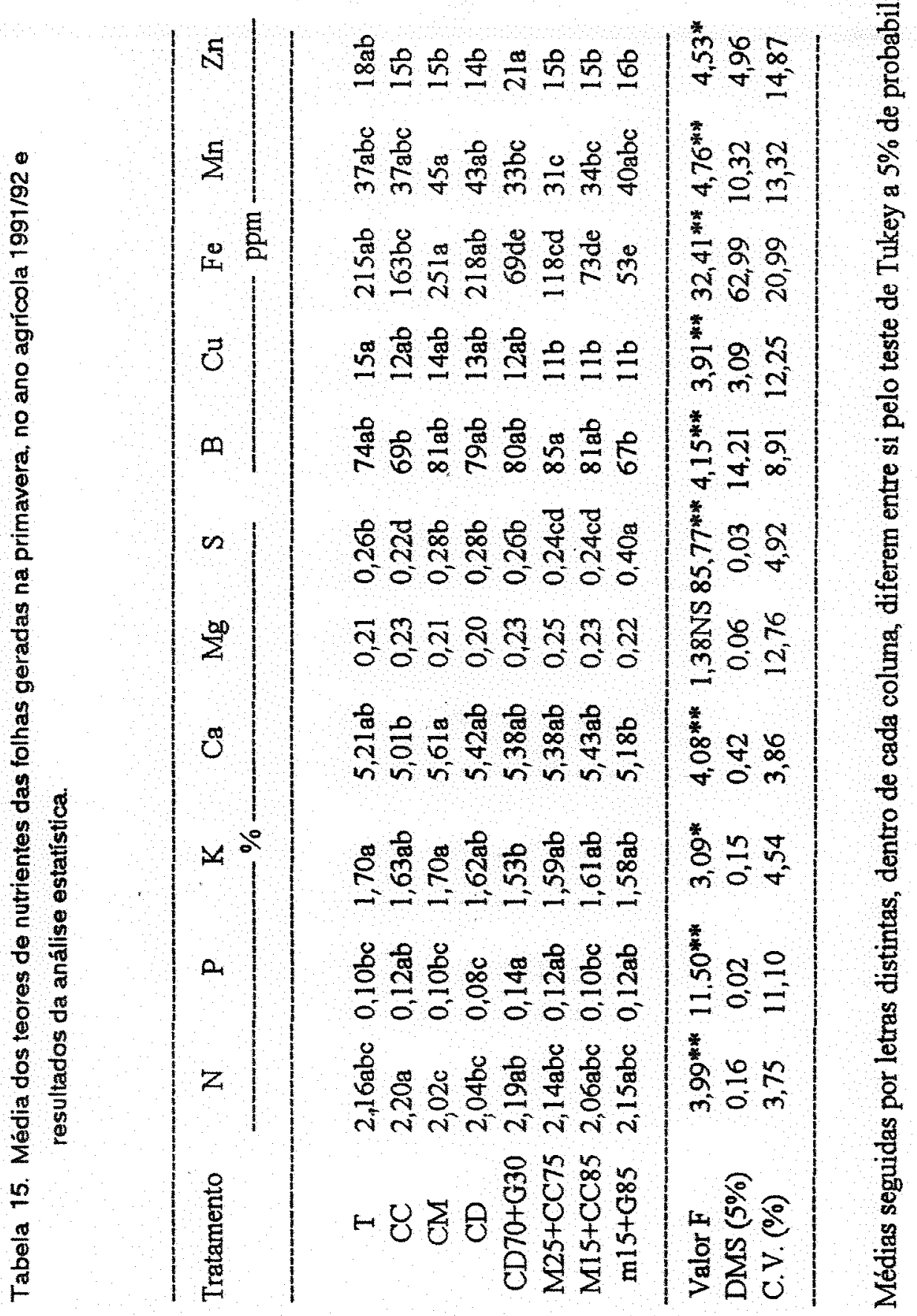
Em função de não fornecer fontes de Ca e Mg para a testemunha, este tratamento apresentou a maior relą̧a o $\mathrm{K} / \mathrm{Ca}$ $+M g$, enquanto o tratamento com aplicação de gesso, mesmo não havendo diferença significativa, a relação foi a menor, em decorrência da lixiviação de $\mathrm{Ca} e \mathrm{Mg}$ no perfil do solo, conforme já discutido.

Com a redução da concentração de Ca e aumento de $\mathrm{K}$, a relą̧ão $\mathrm{Ca} / \mathrm{K}$ se encontra na faixa ideal.

\subsection{Produção de frutos}

Na Tabela 16 estão apresentados os resultados de produção em caixas de $40,8 \mathrm{~kg} / \mathrm{planta,}$ correspondente às colheitas dos anos agrícolas $1991 / 92$ e $1992 / 93$.

$\mathrm{Na}$ produção referente a safra 1991/92 não se obteve diferença significativa entre os tratamentos, o que pode ser explicado pelo tratamento prévio ao início do experimento, bem como os efeitos diretos da aplicação dos corretivos serão sentidos na produção do ano seguinte.

Na safra $1992 / 93$ observou-se que os tratamentos onde houve aplicação dos corretivos apresentaram diferenças significativas em relação a testemunha. Coube ao tratamento M15 + G85 a maior produção absoluta de 4,37 caixas/planta, a qual diferiu significativamente somente dos tratamentos T e M15 + CC85. Depois da testemunha ( 3,58 caixas/planta), o tratamento M15 + CC85 foi o que apresentou a menor produção de frutos $(4,01$ caixas/planta).

o enriquecimento de $\mathrm{Ca}$ no solo, mediante a aplicação de corretivos através dos tratamentos, o qual é exigido ém altas proporções pelo citros (QUAGGIO, 1985), como também a redução de toxidez de Al (LOPES, 1986), propiciam benefícios ao crescimento radicular e a produção, no sentido de aumentar a capacidade de exploração de água e de nutrientes. Enquanto que o uso do gesso, apesar de não promover alteração 
45.

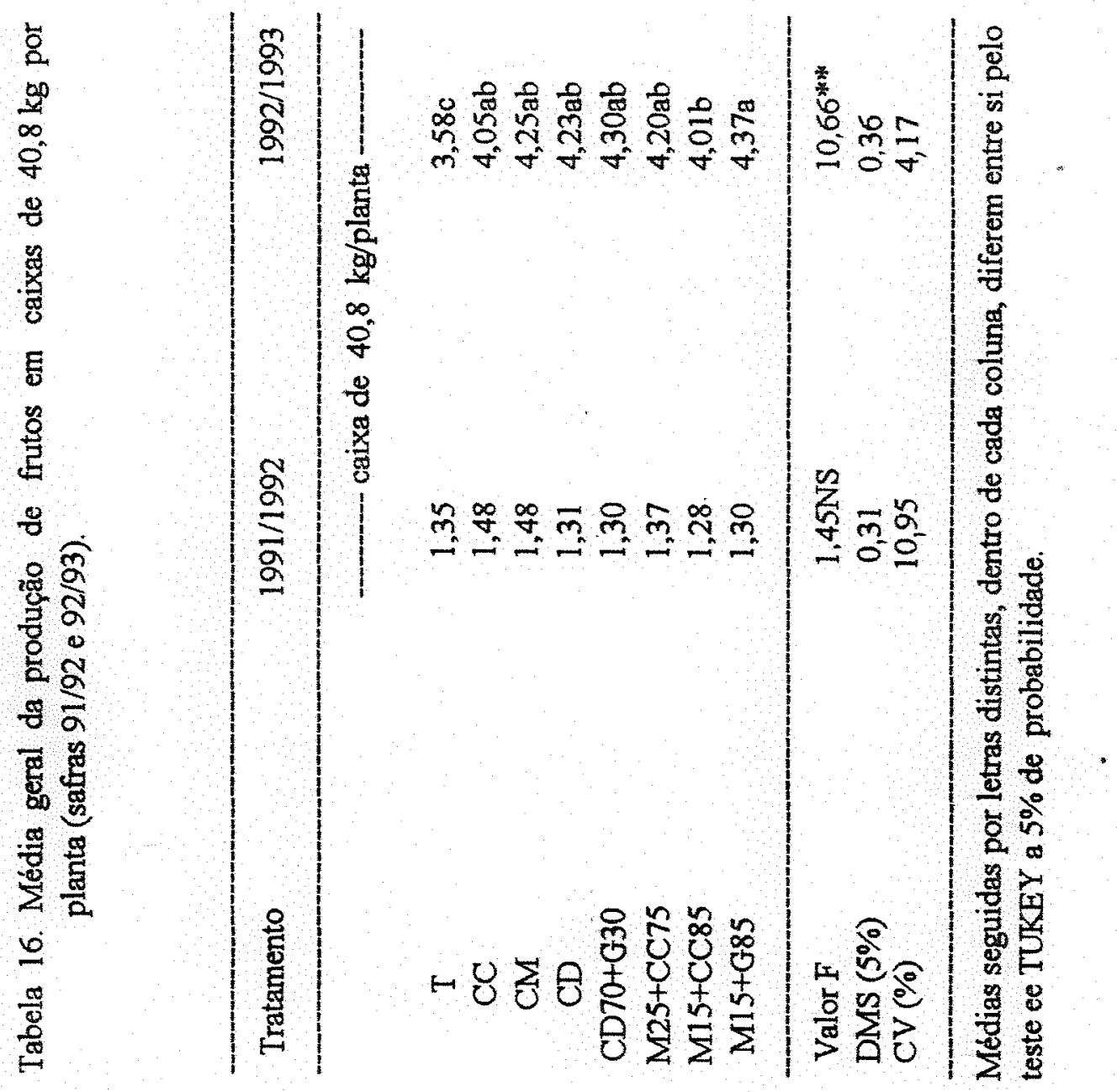


46.

do $\mathrm{pH}$, promove a lixiviação de potássio e magnésio para horizontes inferiores (SOUZA \& RITCHEY, 1986), alem do decréscimo na saturação por alumínio do subsolo (PAVAN et al., 1984; CHAVES et al., 1988), melhorando, assim, as condições do ambiente do subsolo e, dessa forma, resultando em aumento significativo na produção (GUILHERME, 1985).

\subsection{Análises tecnológicas}

4.4.1. Ano agrícola $1991 / 92$

Na Tabela 17 estão apresentados os resultados das análises tecnologicas dos frutos amostrados na safra $1991 / 92$.

Não foram verificadas diferenças significativas entre os tratamentos para os parâmetros Brix, Ratio, peso dos frutos, altura do fruto e diâmetro do fruto. Segundo VIÉGAS (1991), os resultados de Ratio qualificam todos os tratamentos como adequados para a industrialização, uma vez que a faixa adequada varia de 11 a 14 . O autor relatou ser o Ratio o indicador utilizado na determinação do estágio de maturação.

os ácidos têm papel importante no sabor do suco, pois o acentuam (VIEGAS, 1991). Desta forma, o tratamento CC apresentou maior valor de acidez corrigida $(0,81)$, diferindo significativamente dos outros tratamentos.

\subsubsection{Ano agrícola $1992 / 93$}

Na Tabela 18 são mostradas as análises tecnologicas dos frutos referentes a safra $1992 / 93$. Inicialmente, observa-se um aumento em todos os tratamentos para os parâmetros acidez corrigida, Brix e Ratio, em relação ao ano agrícola anterior. Observou-se, também, a resposta não 
47.

significativa do peso de frutos e altura em relação aos tratamentos.

o valor de acidez corrigida do tratamento com calcário dolomítico + gesso diferiu significativamente da testemunha e do tratamento com calcário dolomítico. o valor do Brix do tratamento M15 + CC85 foi significativamente superior à testemunha e aos tratamentos CM e M15 + G85. Os baixos valores de Brix favoreceram o menor valor de Ratio para a testemunha que somente diferiu do tratamento M25 + CC75. Por outro lado, foi o tratamento M25 + CC75 quem apresentou o maior valor de Ratio, diferindo significativamente dos tratamentos $T$, $C M$ e CD70 + G30, entretanto esse valor fora da faixa adequada, a qual foi conseguida pelos tratamentos $T, C M, C D 70+G 30$ e M15 + G85. 
48.

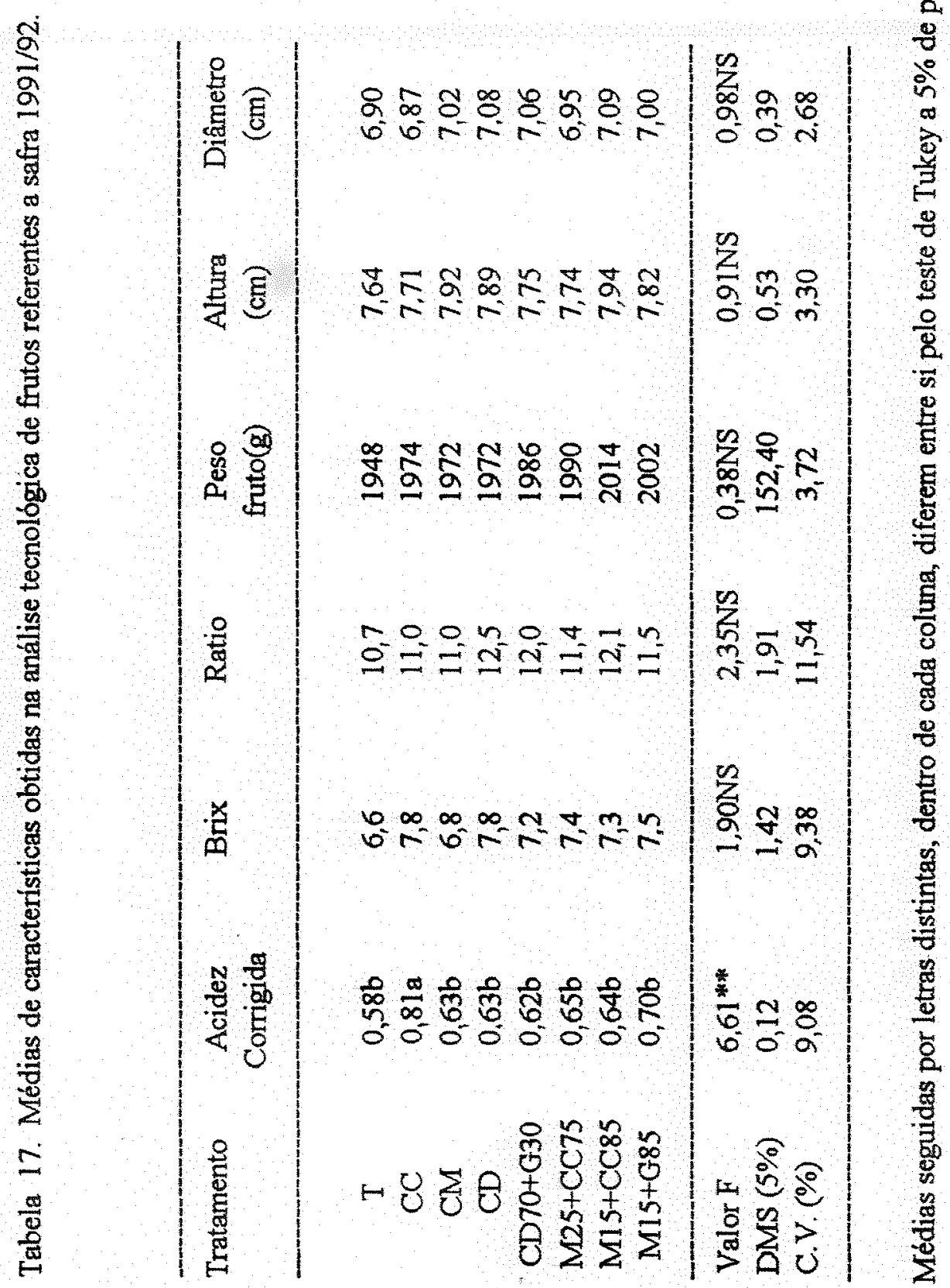




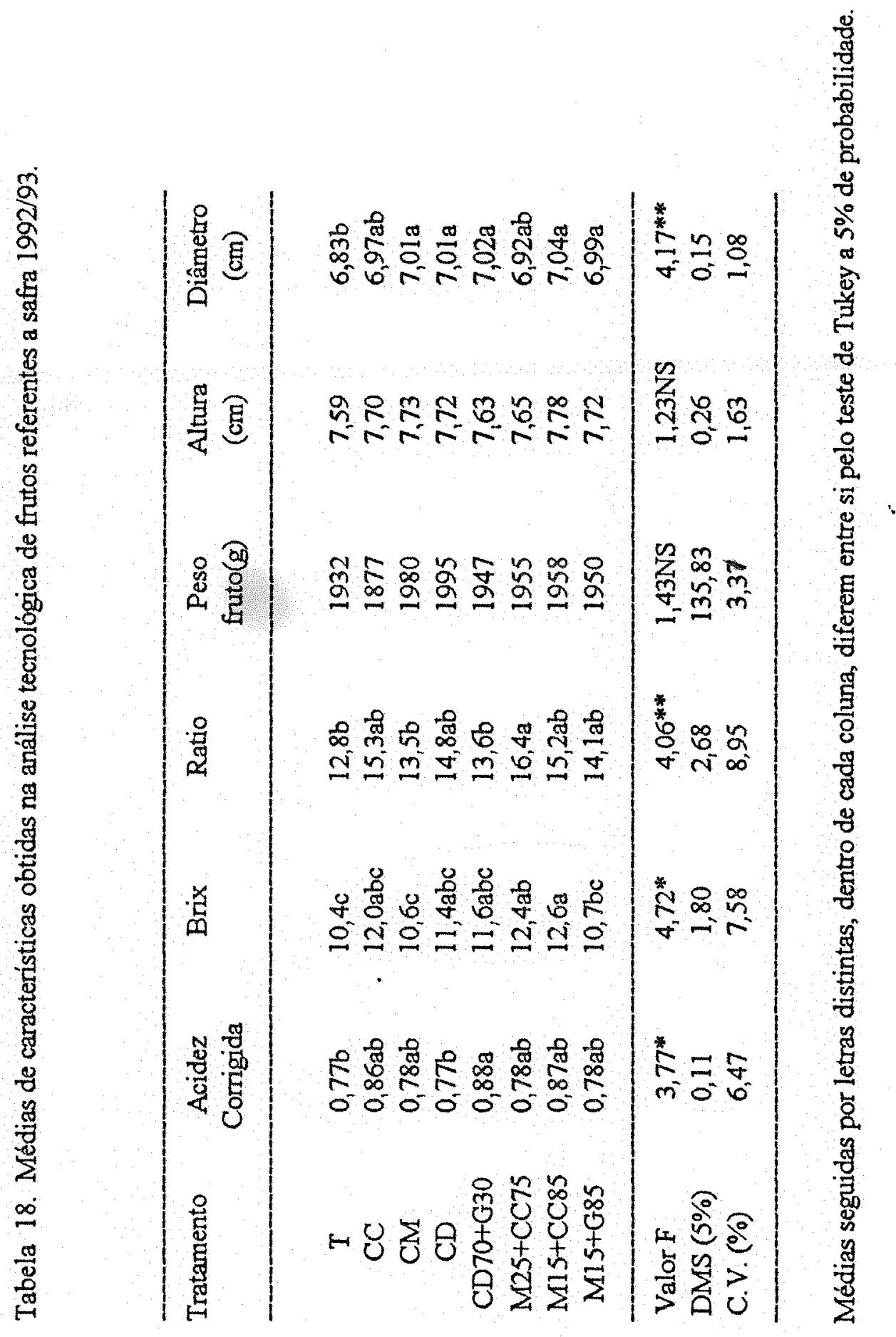

49. 
50.

5. CONCLUSÕES

Com base nos resultados obtidos pode-se concluir que :

1) A aplicação de corretivos promoveu o aumento do $\mathrm{pH}$ e anulou a saturação por alumínio nas três profundidades estudadas;

2) Os tratamentos onde houve inclusão de magnesita proporcionaram eficiente correção da acidez superficial do solo, bem como adequado fornecimento de magnésio;

3) a presença do gesso no tratamento magnesita + gesso proporcionou níveis adequados de $\mathrm{K}, \mathrm{Ca}, \mathrm{Mg}$ e $\mathrm{S}$ ao longo do perfil do solo;

4) A maior produção foi obtida pelo tratamento magnesita + gesso, enquanto o tratamento sem aplicação de corretivos (testemunha) apresentou 'a menor. 
51.

\section{REFERENCIAS BIBLIOGRAFICAS}

ALCARDE, J.C. Corretivos da acidez dos solos: caracteríticas de qualidade. In: MALAVOLTA, E., ed. Seminário sobre corretivos agrícolas. Campinas, Fundação Cargill, 1985. p.97-119.

ANDERSON, C.A. Fruit yields, tree size, and mineral nutrition relation-ship in valencia orange trees affected by liming. J. Plant Nutrition, New York, 10(9-16):1907-16, 1987.

BATAGLIA, O.C.; FURLANI, A.M.C.; TEIXEIRA, J.P.F.; FURLANI, P.R.; GALLO, J.R. Métodos de análise química de plantas. Campinas, Inst ituto Agronômico, 1983. 48p. (Bolet im Técnico, $78)$.

BATAGLIA, O.C.; RODRIGUES, O.; HIROCE, R.; GALLO, J.R.; FURLANI, P.R.; FURLANI, A.M.C. Composição mineral de frutos cítricos na colheita. Bragantia, Campinas, 36:215-22. 1977.

BOWER, C.A. \& PIERRE, W.H. Potassium response of various crops on a high lime relation to their contents of potassium, calcium, magnesium and sodium. J. Am. Soc. Agron., Washington, 36:608-14, 1944 . 
CHAVES, J.C.D.; PAVAN, M.A.; MIYAZAWA, M. Redução da acidez subsuperficial em coluna de solo. Pesq. Agrop. Bras., Brasília, 23:469-76, 1988.

CIPOLLI, J.R. Efeitos da aplicação de calcário calcinado, gesso e misturas calcário-gesso na cultura de citros. Jaboticabal, 1986. 49p. (Graduação - Faculdade de Ciências Agrárias e Veterinárias / UNESP).

COUTO, W.; LATHWELL, D.J.; BOULDIN, D.R. Sulfate sorption by two Oxisols and an Alfisol of the tropics. Soil sci., Baltimore, 127:108-16, 1979 .

DAL BO, M.A. Movimentação de bases e crescimento de raízes de cana-de-açúcar em colunas de solos, em função da adição de diferentes sais de cálcio. Viçosa, 1985. 62p. (MestradoUniversidade Federal de viçosa).

DEFELIPO, B.V.; BERNARDO, S.B.; CIMINELLI, J.G. Relação ideal entre $\mathrm{P}_{2} \mathrm{O}_{5} / \mathrm{MgO}$ e CaO/MgO na produção de milho e soja em um solo de cerTado. In: REUNIÃO BRASILEIRA DE FERTILIDADE DO SOLO E NUTRIÇÃO DE PLANTAS, 19., Santa Maria, 1990. Anais. Santa Maria, Sociedade Brasileira de Ciencia do Solo, 1990. p.37.

DEFELIPO, B.V.; SANTOS, J.F.; SILVA, J.G. Efeito do óxido de magnésio na adubação com superfosfato triplo. In: CONGRESSo BRASILEIRO DE CIENCIA DO SOLO, 22., Recife, 1989. Programa e Resumos, Recife, Sociedade Brasileira de Ciência do solo, 1989. p. 274-5.

DEJOU, J. \& MONTARD, F.X. Efecto positivo que ejercen los obonados potássio y magnésio em suelos vulcánicos del Macizo Central francés. Evolución de $\mathrm{K}^{+}$en el suelo y en la planta 
53.

al final de cinco años de cultivo de ballico perene. Revista de 1 a Potassa, Berna, 7(3):1-10, 1982 .

DEMATTE, J.L.I. Solos arenosos de baixa fertilidade: estratégia de manejo. Palestra apresentada no V Seminário Agroindustrial "Luiz de Queiroz" STAB. XXIX Semana "Luiz de Queiroz", Piracicaba, 1986 .

EMBRAPA. Centro de Pesquisa Agropecuária dos Cerrados. Relatório Técnico Anual, 1980/81. Brasilia, 1982. 163p.

FARINA, M.P.W. \& CHANNON, P. Acid-subsoil amelioration. I. A comparison of several mechanical procedures. Soil Sci. Soc. Am. J., Madison, 52:169-75, 1988a.

FARINA, M.P.W. \& CHANNON, P. Acid-subsoil amelioration. II. Gypsum effects on growth and subsoil chemical properties. Soil Sci.Soc. Am. J., Madison, 52:175-80, $1988 \mathrm{~b}$.

FOY, C. D. Physiological effects of hydrogen, aluminum, and manganese toxicities in acid soil. In: ADAMS, F, ed. Soil acidity and 1 iming. 2.ed. Soil Science Society of America, Madison, 1984 . p. 57-97.

GRUPO PAULISTA DE ADUBAÇス̃O E CALAGEM PARA CITROS - Recomendações de adubação e calagem para citros no Estado de São Paulo. Laranja, Cordeirópolis, $9(3): 1-14,1988$.

GRUPO PAUL ISTA DE ADUBAÇÃO E CALAGEM PARA CITROS. Recomendações de adubação e calagem para citros no Estado de são Paulo. 2.ed. Laranja, Cordeiropolis, 11(3):1-14. 1990. 
GUILHERME, M.R. Efeitos da aplicação de calcário calcinado, gesso e misturas de calcário dolomítico calcinado e gesso em culturas de interesse econômico. Piracicaba, 1986, 56p. (Mestrado - Escola Superior de Agricultura "Luiz de Queiroz"/USP).

HAMMEL, J.E.; SUMNER, M.E.; SHAHANDEH, H. Effect of physical and chemical profile modification on soybean and corn production. Soil Sci. Soc. Am. J., Madison, 49:1508-11, 1985 .

KAMPFER, M, \& UEXKULL, H.R. von. Nuevos conocimientos sobre la fertilización de los citricos. 3.ed. Hanover, Verlag Gesselschaft fur AcKerbau, 1966. $104 \mathrm{p}$.

LOPES, A.S. Calagem e gesso agrícola. In: ENCONTRO TÉCNICO SOBRE GESSO AGRfCOLA. Belo Horizonte, 1986. 58p. (mimeografado).

LOPES, A.S. Manual de fertilidade do solo. Piracicaba, Associação Brasileira para Pesquisa da Potassa e do Fosfato, 1989. $155 \mathrm{p}$.

MALAVOLTA, E. Nutrição mineral e adubação da laranjeira. Piracicaba, ESALQ/USP, 1979. p. 99-122 (Boletim Técnico, 6).

MALAVOLTA, E. Elementos de nutrição mineral de plantas. São Paulo, Ed. Agronômica Ceres, 1980. 252p.

MALAVOLTA, E. Manual de química agrícola; adubos e adubações 3. ed. São Paulo, Editor Agronômica Ceres, 1981, 596p.

MALAVOLTA, E. Nutrição mineral, calagem, gessagem e adubação dos citros. Laranja (9):01-52, 1988. 
MALAVOLTA, E.; CROCOMO, O.J.; ANDRADE, R.G.; ALVIZURI, C.; VENCOWSKY, R.; FREITAS, L.M.M. Estudos sobre a fertilidade dos solos do cerrado. I. Efeito da calagem na disponibilidade do fósforo (Nota Prévia). An. E.S.A. "Luiz de Queiroz", 22:131-8, 1965.

MALAVOLTA, E.; GUILHERME, M.R.; LIEN, T.H. Associação fosfogesso-calcário; princípios e aplicações. In: SEMINARIO SOBRE O USO DO FOSFOGESSO NA AGRICULTURA, 1., Brásília, 1986. Anais. Brasília, EMBRAPA-DDT, 1986. p.177-98.

MALAVOLTA, E. \& VIOLANTE NETTO, A. Nutrição mineral, calagem, gessagem e adubação dos citros. Piracicaba, Associação Brasileira para Pesquisa da Potassa e do Fosfato, 1989. $153 \mathrm{p}$.

Malavolta, E.; VitTi, G.C.; OLIVEIRA, S.A. de. Avaliação do estado nutricional das plantas; princípios e aplicações. Piracicaba, Associação Brasileira para Pesquisa da Potassa e do Fosfato, 1989. 201p.

MARTINS, o.C. Comportamento da soja e do trigo e alterações no perfil do solo em resposta à aplicação de diferentes misturas de calcário e gesso. Viçosa, 1990. 81p. (MestradoUniversidade Federal de Viçosa).

MENDES, L.D.T. A maturação dos frutos cítricos. São Paulo: Departamento de fomento da produção vegetal, Seção de Fruticultura, 1976. 9p. (Circular, 3).

MENGEL, K. \& KIRKBY, E.A. Principles of plant nutrition. 3. ed. Berne-Switzerland, Int. Potash. Inst., 1982, 655p. 
NEPTUNE, A.M.L. O magnésio como nutriente para as culturas. In: SILVA, M.c. de, Coord. Seminario fósforo, cálcio, magnésio, enxofre e micronutriente: situação atual e perspectivas na agricultura. Anais. São Paulo, Manah S/A, 1986. p. 74-82.

OLIVEIRA, J.B. Solos para a citricultura no Estado de São Paulo. Laranja, Cordeirópolis, 7(1):337-51, 1986.

Olmos, J.I.L. \& CAMARGo, M.N. Ocorrência de alumínio tóxico nos solos do Brasil, sua caracterização e distribuição. Ciência e Cultura, São Paulo, 28(2):171-80, 1976 .

OLSEN, S.R. \& WATANABE, F.S. Interaction of added gypsum in alkaline soils with uptake of iron, molybdenum, manganese and $z$ inc by sorghum. Soil Sci. Soc. Am. J., Madison, 43:125$30,1979$.

PAOLINELLI, M.T.; OLIVEIRA, P.M.; SANTOS, P.R.R.S.; LEANDRO, V.P.; MORAES, W.V. Aplicą̧ão direta do fosfogesso. In: SEMINARIO SOBRE O USO DO FOSFOGESSO NA AGRICULTURA, 1., Brasília, 1986. Anais. Brasília, EMBRAPA/DDT, 1986. p.197207.

PAVAN, M.A. O cálcio como nutriente para as culturas. In: SILVA, M.C. de, Coord. Seminário fósforo, cálcio, magnésio, enxofre e micronutrientes - situação atual e perspectivas na agricultura. Anais. São Paulo, Manah S/A, 1986. p.82-6.

PAVAN, M.A.; BINGHAM, F.T.; PRATT, P.F. Toxicity of aluminum to coffee in Ultisols and $\mathrm{Oxisols}$ amended with $\mathrm{CaCO}_{3}, \mathrm{MgCO}_{3}$ and $\mathrm{CaSO}_{4} \cdot 2 \mathrm{H}_{2} \mathrm{O}$. Soil Sci. Soc. Am. J., Madison, 46:1201-7, 1982 . 
PAVAN, M.A.; BINGHAM, F.T.; PRATT, P.F. Redistribution of exchangeable calcium, magnesium, and aluminum following 1 ime or gypsum applications to a Brazilian Oxisol. Soil Sci. Soc. Am. J., Madison, 48:33-8, 1984 .

PIMENTEL GOMES, F. Curso de estatistica experimental, 11 ed. Piracicaba, ESALQ, 1985. 466P.

QUAGGIO, J.A. Calagem para citros no Estado de são Paulo. Revisão nos métodos de recomendação. Ed. Planta Cítrica, $1: 1-10,1982$.

QUAGGIO, J.A. Calagem para citros, Laranja. Cordeirópolis, $6: 167-78,1985$.

QUAGGIO, J.A.; DECHEN, A.R.; RAIJ, B. van. Efeitos da aplicação de calcário e gesso sobre a produção de amendoim e lixiviação de base no solo. R. Bras. Ci. Solo, Campinas, $6: 189-94,1982$.

QUAGGIO, J.A.; SOBRINHO, J.T.; DECHEN, A.R. Relações entre as bases no solo e produtividade da laranjeira. In: REUNIÃO BRASILEIRA DE FERTILIDADE DO SOLO E NUTRIÇÃO DE PLANTAS. Adubação, Produtividade e Ecologia, 20. Anais. Piracicaba, SBCS, 1992. p.146-7.

RAIJ, B. van. Acidez do solo e calagem. In: CURSO DE ATUALIZAÇÃO EM, FERTILIDADE DO SOLO, Londrina, 1983. Trabalhos apresentados.Londrina, IAPAR, 1983.p.65-87.

RAIJ, B. van. Fertilidade do solo e necessidade de calcário e fertilizantes para o Estado de São Paulo. O Agronómico, Campinas, $37: 13-21,1985$. 
58.

RAIJ, B. van. Gesso agrícola na melhoria do ambiente radicular no subsolo. São Paulo, Associação Nacional para Difusão de Adubos e Corretivos Agrícolas, 1988 . 88p.

RAIJ, B. van. \& QUAGGIO, J.A. Metodos de analise de solo para fins de fertilidade. Campinas, Instituto Agronômico, 1983. 31p. (Boletim Técnico, 81).

RAIJ, B. van. \& ZULLo, M.A.T. Metodos de analise do solo. Campinas, Instituto Agronômico, 1977. 17p. (Circular, 63).

REEVE, N.G. \& SUMNER, M.E, Ame lioration of subsoil acidity in natal oxisols by leaching of surface-applied amendments. Agrochemophysica, Pretoria, 4:1-6, 1972 .

RIRIE, D.; TOTH, S.J.; BEAR, F.E. Moviment and effect of lime and gypsum. Soil sci., Balt imore, 73:20-35, 1952 .

RITCHEY, K.D.; SILVA, J.E.; SOUZA, D.M.G. Deficiência de cálcio e crescimento de rá́zes em solos de cerrado. In: CONGRESSO BRASILEIRO DE CIENCIA DO SOLO, 18., Salvador, 1981. Programas e Resumos, Salvador, Sociedade Brasileira de Ciência do solo, 1981. p.96.

RITCHEY, K.D.; SOUZA, D.M.G.; LOBATO, E.; CORREA, C. Calcium leaching to increase rooting depth in Brazilian savannah Oxisol. Agron. J., Madison, 70:40-4, 1980 .

ROBINSON, N. Phosphoric acid technology. In: KHASAWNEH, F.E.; SAMPLE, E.C.; KAMPRATH, E.J., eds., The Role of Phosphorus in Agriculture. Am. Soc. Agronomy, Madison, 1980. p.151-93. 
ROSOLEM, C.A. \& MACHADO, J.R. Efeitos da calagem e gessagem na produção de algodão e na lixiviação de bases em dois latossolos. R. bras. Ci. Solo, Campinas, 8:103-9, 1984.

SARRUGE, J.R. \& HAAG, H.P. Análises químicas em plantas. Piracicaba, Livroceres, $1974.55 \mathrm{p}$.

SILVA, J.G. \& DEFELIPO, B.V. Resposta do eucalipto à aplicação de óxido de magnésio e gesso. In: CONGRESSO BRASILEIRO DE CIENCIA DO SOLO, Recife, 22, , 1989. p.276.

SOARES, E. Influência da relação entre teores trocáveis de cálcio e magnésio do solo na absorção de potássio pelo centeio (Secale cereale L.). Piracicaba, 1975. 73p. (Mestrado - Escola Superior de Agricultura "Luiz de Queiroz"/USP).

SOUZA, D.M.G.; REIN, T.A.; LOBATO, E.; RITCHEY, K.D. Métodos para recomendação de gesso em solos de cerrado. In: REUNIÃo BRASILEIRA DE FERTILIDADE DO SOLO E NUTRIÇÃO DE PLANTAS, 20. Piracicaba, 1992, p.362-3.

SOUZA, D.M.G. \& RITCHEY, K.D. Uso do gesso no solo de cerrado. In: SEMINARIO SOBRE O USO DO FOSFOGESSO NA AGRICULTURA, 1., Brasília, 1986. Anais. Brasília, EMBRAPA-DDT, 1986. P.11944.

SUMNER, M.E.; SHAVANDEH, H.; BOUTON, J.; HAMMEL, J.E. Amelioration of an acid soil profile through deep liming and surface application of gypsum. Soil Sci. Soc. Am. J., Madison, 50:1254-78, 1986 .

TISDALE, S.L.; BEATON, J.D.; NELSON, W.L. Soil fertility and fertilizers. 4.ed. New York, McMillan, 1985. 754p. 
60.

VIÉGAS, F.C.P. Industrializą̧ão dos citros. In: CURSo INTENSIVO DE CITRICULTURA. Piracicaba, A.E.C. Ceres/ESALQ, 1991 . p. 195-206.

VITTI. C.G. Acidez e calagem do solo. Laranja, Cordeirópolis, $5: 77-102,1984 a$.

VITTI, G.C. Interpretação de análise de solo e alternativas de uso de adubos e corretivos. In: DONADIO, L.C., ed.' Simpósio sobre produtividade de citros, 1., Jaboticabal, $1984 \mathrm{~b}$. p.127-54.

VITTI, G.C. Acidez do solo, calagem e gessagem. In: CURSO DE ATUALIZAÇAO DO SOLO. 1., I lha SOlteira, 1987. p.301-48.

VITTI, G.C. Avaliação e interpretação do enxofre no solo e na planta. Jaboticabal, FUNEP, 1989. 37p.

VITTI, G.C. \& DONADIO, L.C. Corrę̧ão do solo e micronutrientes. In: SIMPÓSIO DE CITRICULTURA, 3. Anais. Jaboticabal, FCAV-FUNEP, 1988, p.163-83.

VITTI, G.C.; FERREIRA, M.E.; MALAVOLTA, E. Respostas de culturas anuais e perenes. In: SEMINARIO SOBRE $O$ USO DO FOSFOGESSO NA AGRICULTURA, 1., Brasilia, 1986. Anais . Brasília, EMBRAPA-DDT, 1986. p.17-43.

VITTI, G.C.; MALAVOLTA, E.; FERREIRA, M.E. Respostas de culturas anuais e perenes a aplicação de enxofre. In: BORKERT, C.M. \& LANTMANN, A.F., eds., Enxofre e micronutrientes na agricultura brasileira. Anais. Londrina, EMBRAPA/CNPSO/IAPAR/SBCS, 1988. p.61-85. 
YORK, E.T.; BRADFIELD, R.; PEECH, M. Calcium interaction in soils and plant. II. Reciprocal relation ships between calcium and potassium in plants. Soil Sci., Baltimore, 76: $481-91,1953$. 